\title{
Development of Advanced Textile Finishes Using Nano-Emulsions from Herbal Extracts for Organic Cotton Fabrics
}

\author{
Prabhuraj D. Venkatraman ${ }^{1, * \mathbb{D}}$, Usha Sayed ${ }^{2}$, Sneha Parte ${ }^{2} \mathbb{D}$ and Swati Korgaonkar ${ }^{2} \mathbb{D}$ \\ 1 Manchester Fashion Institute, Manchester Metropolitan University, Cavendish Street, \\ Manchester M15 6BG, UK \\ 2 Department of Fibres and Textile Chemistry, Institute of Chemical Technology (ICT), Nathalal Parekh Marg, \\ Matunga, Mumbai 400 019, India; u.sayed@ictmumbai.edu.in (U.S.); snhprt37@gmail.com (S.P.); \\ swatikorgaonkar25@gmail.com (S.K.) \\ * Correspondence: p.venkatraman@mmu.ac.uk
}

Citation: Venkatraman, P.D.; Sayed, U.; Parte, S.; Korgaonkar, S.

Development of Advanced Textile

Finishes Using Nano-Emulsions from Herbal Extracts for Organic Cotton

Fabrics. Coatings 2021, 11, 939.

https://doi.org/10.3390/

coatings11080939

Academic Editor: Chi-wai Kan

Received: 16 June 2021

Accepted: 2 August 2021

Published: 5 August 2021

Publisher's Note: MDPI stays neutral with regard to jurisdictional claims in published maps and institutional affiliations.

Copyright: (c) 2021 by the authors. Licensee MDPI, Basel, Switzerland. This article is an open access article distributed under the terms and conditions of the Creative Commons Attribution (CC BY) license (https:/ / creativecommons.org/licenses/by/ $4.0 /)$.

\begin{abstract}
The development of textile finishing with improved functional properties has been a growing interest among industry and scientists worldwide. The recent global pandemic also enhanced the awareness amongst many toward improved hygiene and the use of antimicrobial textiles. Generally, natural herbal components are known to possess antimicrobial properties which are green and eco-friendly. This research reports a novel and innovative method of developing and optimising nano-emulsions using two combinations of herbal extracts produced from Moringa oleifera, curry leaf, coconut oil (nano-emulsion 1) and other using Aegle marmelos with curry leaf and coconut oil (nano-emulsion 2). Nano-emulsions were optimised for their $\mathrm{pH}$, thermal stability, and particle size, and percentage add-on. Organic cotton fabrics (20 and $60 \mathrm{gsm}$ ) were finished with nano-emulsions using continuous and batch processes and characterised for their surface morphology using scanning electron microscopy, energy dispersive X-ray (EDX) analysis and Fourier transform infrared spectroscopy (FTIR) analysis. The finished fabrics were evaluated for their Whiteness Index, assessed for antimicrobial resistance against Gram-positive (Staphylococcus aureus) and Gram-negative bacteria (Escherichia coli) using AATCC 100 and 147 methods. In addition, fabrics were assessed for their antifungal efficacy (AATCC 30), tensile strength and air permeability. Results suggested that finished organic fabrics with nano-emulsions had antimicrobial resistance, antifungal, wash fastness after 20 washing cycles, and sufficient strength. This novel finishing method suggests that organic cotton fabrics treated with nano-emulsions can be used as a durable antimicrobial textile for healthcare and hygiene textiles.
\end{abstract}

Keywords: Moringa oleifera; Aegle marmelos; organic cotton; nano-emulsion; antimicrobial resistance; antifungal efficacy; wash fastness

\section{Introduction}

Cotton based textile fabrics retain sufficient moisture [1], offer a large surface area, can absorb moisture from the environment and human body and maintain body temperature. These properties of cotton fabrics serve as an ideal environment for the growth of fungi and microbes. Studies have shown the survival of several Gram-positive bacteria (Staphylococcus aureus, Enterococcus faecalis) on standard hospital fabrics made of $100 \%$ cotton clothing, $100 \%$ cotton terry towels, $60 \% / 40 \%$ cotton/polyester-scrub suits and lab coats, and $100 \%$ polyester drapes. Swatches were inoculated with micro-organisms and examined for growth over $48 \mathrm{~h}$. Most bacterial growth survived at least a day, and some survived more than 90 days [2]. High survival of bacteria through textiles leads to the spread of infections requiring proper hygiene, procedures to control infections, and disinfection of contact surfaces and textiles [3]. This also shows that textiles made of natural fibres 
(cotton) are more susceptible to microbial growth, especially when they contact the body and moist objects leading to transmission of infections [3]. In order to counteract the microbial attack, textiles intended for medical and hygiene applications are treated with a range of antimicrobial finishes obtained from chemicals, including quaternary ammonium compounds, triclosan, metallic salts $\left(\mathrm{TiO}_{2}, \mathrm{ZnO}\right)$, chitosan, phenolic compounds, oxidising agents, and poly (hexamethylene biguanide) [4].

Textiles (cotton, silk, and bamboo) were treated with natural extracts such as resveratrol, a natural polyphenol, obtained from Polygonum cuspidatum (Japanese knotweed), also widely found in fruits, such as grapes, red wine, mulberries, and other fruits and were reported to possess pharmacological activities-Antibacterial, antifungal, and antiinflammatory properties [5]. Bio-functional textiles can be defined as those textiles treated with biocompatible materials with drug delivery systems, widely preferred in medical applications [6]. In addition, bio-functional textiles can absorb from the skin or release therapeutic or cosmetic compounds [7]. Textiles are finished using a variety of methods and techniques, however in addition to the traditional finishing techniques, padding or continuous process (involves dipping the fabric in the bath and squeezing between the rollers) and exhaust or batch process (involves immersion of fabrics in the liquor bath and rotating in the bath for a given period), layer-by-layer deposition method has been recently developed. This involves dipping the textiles in an electrically charged electrolyte where a monolayer of the film is deposited [8]. Other innovative methods of developing bio-functional textiles include using a confined impinging jet mixer (CIJM) to produce nanoparticles of menthol loaded poly-e-caprolactone [9]. Furthermore, ultrasound irradiation assisted water/oil/water microemulsion method of producing nano-capsules $(60-80 \mathrm{~nm})$ of chamomile extracts on cotton fabrics using UV curing were also reported to have good antimicrobial properties [10]. Recently, nanoparticles were developed using the flash nanoprecipitation technique (FNP) to produce bio-functional cotton/micro-modal textiles with caffeine for transdermal applications [11].

The FNP method has also been demonstrated to entrap caffeine in poly- $\varepsilon$-caprolactone with control release [12]. Various nanoparticles were deposited on polyester/cotton or cotton fabrics with gold, silver, $\mathrm{ZnO}$, or $\mathrm{TiO}_{2}$ particles showing good antibacterial and antifungal activity [13]. A decrease in particle size shows better antibacterial results due to the high surface area to volume ratio and increases its wash durability, and the adhesion of nanoparticles onto the textiles can be affected using surfactant [13]. Several methods of surface modification of textiles with antimicrobial properties were also highlighted recently, including nanoparticle technology, micro and nano-capsules, vapour deposition, sol-gel, and encapsulation [14].

Antimicrobial chemicals or material can inhibit bacterial cell growth, called the biostatic effect, or kill micro-organisms known as the biocidal effect $[15,16]$. Most antimicrobial agents used in textiles are biocides [17]. Biostatic inhibits micro-organisms' growth, prevents odour control, and preserve textiles leaving live bacteria on the surface. Although the infection rate can be reduced, it leaves the residual micro-organisms that could cause transmission of infection. Biocidal kill the micro-organism in a short contact time, provide complete disinfection of diseases on the surface, and prevent transmission of infections in a hospital setting [18]. The resistance level also depends on the dosage of the antimicrobial agent, the affinity of the antibacterial agent finishing on textiles and its end-use.

Many synthetic chemicals are toxic and may not decompose quickly, affecting aquatic organisms when washed into streams. When released from textiles into waste waterways, synthetic antimicrobial agents can affect the aquatic environment when not recovered or recycled. The biodegradability of QACs (quaternary ammonium compounds) is poor [19]. Degradation of triclosan is also a concern and can be toxic, and research also highlighted environmental and health problems of various antimicrobials (triclosan, quaternary ammonium compounds, and copper) and risk associated with triclosan [20]. The most silverbased and mineral-based product cannot be biodegradable [21], as it is a mineral substance. It was reported that many synthetic chemicals could ideally be replaced with natural 
or plant-based compounds, which do not have any adverse effects [4]. The plant-based herbal oils for environmentally-friendly antimicrobial efficacy have been highlighted [4,22]. Plant-based substances provide an efficient antimicrobial resistance. They are safe, widely available, non-toxic, and environmentally friendly $[23,24]$. In addition, the application of enzymes in textile wet processing had been reported to have many advantages, such as reduced use of chemicals, water, and energy, resulting in eco-friendly products [25]. The use of biopolymers (such as chitosan, chitosan nanoparticles, cyclodextrins) for finishing cellulose fabrics with functional properties (antibacterial) have also been reported [26].

Ideally, antimicrobial textiles should inhibit the growth of a broad range of bacteria and fungi, exhibit low toxicity, non-allergic, meet standards for compatibility-cytotoxicity, irritation, and sensitisation. In addition, the finish should be durable during washing, possess strength, appearance, and be compatible with textile chemical processing-dyeing, and not harmful to the environment $[15,27]$. Textile treated biocides either protect the textile or user from microbial growth. Due to recent environmental awareness, several natural bioactive agents, such as chitosan, neem, aloe vera, tea tree, prickly chaff flower, eucalyptus oil, clove oil, curcumin, hiba oil, and natural dyeing materials were of focus, and studies have discussed the development of eco-friendly and antimicrobial textiles [28]. Various natural dyes [29] were also evaluated for the antimicrobial finish of cotton fabrics against Gram-positive and Gram-negative bacteria. Among many natural dyes, $Q$. infectoria (Aleppo Oak) natural dye extract showed good resistance (70-90\%) to most microbes when combined with alum or copper mordants against $45-60 \%$ inhibition of bacterial growth without mordants. In addition, tannin, a water-soluble polyphenol found in many plant and tree species (bark, leaf, root), also possess antimicrobial activity against a wide range of bacteria and fungi [30]. Evaluation of total phenolic content and flavonoids content using leaf extracts (eucalyptus and lemon grass) with methanol, ethanol, chloroform, and distilled water extract indicated the potential of antimicrobial application of textiles [31]. There were also reports on the use of curry leaf and ginger oil showing good antibacterial and antifungal resistance on plain-woven cotton fabric [32].

Moringa oleifera, which belongs to the Moringaceae family, commonly called drumstick tree or horseradish tree, grows in tropical and subtropical regions widely found in India. Moringa leaves and drumsticks are widely consumed as a healthy food by Asians [33]. Leaves of M. oleifera is rich in calcium, potassium, zinc, magnesium, iron, and copper [34]. Apart from its rich nutritive potential, the leaves of $M$. oleifera possess flavonoids that give its antioxidant properties. It is used to treat many diseases, including asthma, flu, diarrhoea, headaches, skin diseases, eye and ear infections [34]. A recent study highlighted the antimicrobial resistance to Bacillus subtilis, Staphylococcus aureus and Vibrio cholera using extracts prepared from moringa seeds [35]. Rockwood et al. (2013) reported the antimicrobial efficacy of $M$. oleifera seeds and leaves using different solvents-deionised water, inorganic ethanol and organic ethyl acetate on 14 micro-organisms [36]. They reported that leaf and seed extracts prepared with ethanol and ethyl acetate showed no inhibition. However, leaf extracts with deionised water showed inhibition against Bacillus sphaericus, and seed extracts inhibited Bacillus sphaericus, Mycobacterium smegmatis, S.aureus and Alcaligenes faecalis. They concluded that Moringa seed extracts were effective than leaf extracts inhibiting bacterial growth. More recently, the use of fresh leaves of Moringa oleifera prepared by water and methanol extracts showed varied levels of antibacterial activity against P. aeruginosa, Klebsiella pp., E. coli and Staphylococcus spp. isolates [37].

Similarly, Aegle marmelos (also commonly called Bael), widely grown in India-outer Himalayas, Shivaliks, South Indian plateau, has shown potential antimicrobial properties. Its leaves, fruits, stems and roots are used for treating various ailments [38]. Several compounds have been noted with Bael, but eugenol [39] and cuminaldehyde [40] are responsible for providing antibacterial properties. Cuminaldehyde is a class of benzaldehydes substituted by isopropyl alcohol at position 4 [41] (see Figure 1). Leaf extracts of Bael have shown antibacterial resistance against Escherichia coli [42,43]. Oil extracts of Bael also have shown resistance against Pseudomonas salacearum, Xanthomonas vesicatoria, Escherichia 
coli, and Aeromonas sp. [44,45]. Therefore, it can be inferred that both Moringa oleifera and Aegle marmelos possess antimicrobial resistance. However, neither of these herbal extracts have been reported for their potential on cotton-based textiles, particularly for their durability and other physical and comfort properties. Based on the above findings, this project focuses on the herbal-based finishing of cotton-based fabrics with antibacterial and antifungal properties, which can be widely produced and used in the community. The application of fabrics with nano-emulsions by the continuous or batch process is available in the local community (urban and rural parts of India). Nano-emulsion shown in this study is easy to prepare (using a simple homogeniser-a high-speed stirrer). Other new methods, comparatively, require more considerable investment resulting in high-end fabrics. Therefore, the padded or exhaust finished fabrics allow the adsorption of sufficient nano-emulsion on the cotton fabrics, producing durable finishing with antibacterial properties. This study reports for the first time the development of herbal nano-emulsions using Moringa oleifera and Aegle marmelos blended with curry leaves and coconut oil. Organic cotton fabrics (varying fabric density) were finished with the above nano-emulsion using continuous (padding) and batch methods (exhaust), and their antimicrobial resistance before wash, after 10 and 20 wash cycles, are presented. The particle size analysis, the $\mathrm{pH}$, the thermal stability, and the percentage add-on of the nano-emulsions were analysed to determine the optimum processing conditions. The main novelty in this project is in the development of a unique combination of herbal nano-emulsions (using Moringa oleifera, Aegle marmelos, curry leaves, and pure coconut oil), its application on organic cotton fabrics and the antibacterial and antifungal resistance of finished fabrics to a wide range of Gram-positive, Gram-negative bacteria and fungi.<smiles>C=CCc1ccc(O)c(OC)c1</smiles><smiles>CC(C)c1ccc(C=O)cc1</smiles>

Figure 1. Compounds of Aegle marmelos.

\section{Materials and Test Methods}

\subsection{Materials}

Organic cotton fabrics-20 g/ $\mathrm{m}^{2}$ (plain weave) and $60 \mathrm{~g} / \mathrm{m}^{2}$ (twill weave) certified by GOTS (Global Organic Test Standards) was supplied by Test fab India (Vapi, Gujarat, India). These lightweight fabrics were selected with the scope of using the finished fabrics as durable wipes. The leafy herbs-Moringa oleifera, Aegle marmelos, curry leaves (Murraya koengii), and odourless pure coconut oil were purchased from Matunga, Mumbai. The surfactant polysorbate monobate 80 (a natural vegetable emulsifier) was purchased from LOBA Chemicals, Mumbai, India, while ethanol was purchased from Himedia Chemicals, Mumbai, India. Polysorbate 80 is a non-ionic surfactant, a viscous liquid which has a yellow to amber colour and is approved by FDA (The Food and Drug Administration, US) [46]. It is widely used in cosmetic, food, and pharmaceuticals industries [47] (Figure 2). 


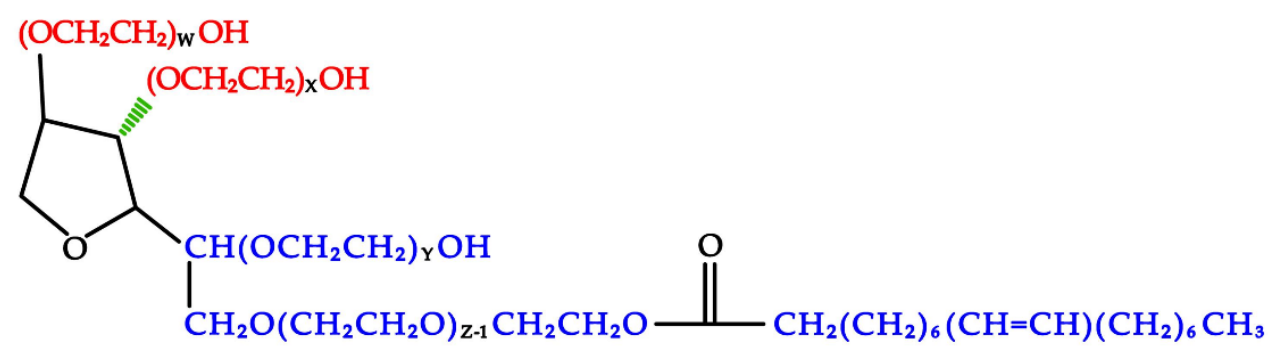

Where $W+X+Y+Z=20$ represents one monomer

Figure 2. Polysorbate 80 (glycol).

The selection of herbal combinations (Moringa oleifera, Aegle marmelos, curry leaf, coconut oil) was based on an extensive survey of herbal constituents, and the proportions of each constituent were based on several trials. Aegle marmelos and Moringa oleifera, curry leaves and coconut oil are consumed as food substances in routine Asian cuisine [34,48-50], and it is anticipated that these nano-emulsions will not cause any adverse effects. Therefore, the fresh leaves of Moringa oleifera and Aegle marmelos were used to prepare different herbal extracts and to this extract, curry leaves and coconut oil were added to produce the two combinations-nano-emulsion 1 (Moringa oleifera, curry leaf and coconut oil) and nanoemulsion 2 (Aegle marmelos, curry leaf and coconut oil).

\subsection{Methodology of Herbal Extraction}

i. $\quad$ Extraction of oil: Both the herbs (Moringa oleifera and Aegle marmelos) were washed thoroughly with the distilled water and dried in the oven at $105^{\circ} \mathrm{C}$ for one hour to remove all the dirt and impurities.

ii. Steam Distillation: The dried herb of $10 \mathrm{gm}$ of Moringa oleifera, $5 \mathrm{gm}$ of curry leaves and $100 \mathrm{~mL}$ coconut oil have been boiled by heating these constituents using steam supplied from a steam generator. The heat applied determines how effectively the plant material structure breaks down and bursts and releases the aromatic components of essential oils. Thus, the steam distillation extraction technique increases the isolated essential oil yields and reduces wastewater produced during the extraction process.

iii. Solvent extraction: The mixture is further used for the extraction of oil through the solvent extraction technique. The solvent used for extraction is $99 \%$ pure ethanol. The dried herbs are kept in the thimble of the Soxhlet extractor, and ethanol solution has been added. The extracted solution has been collected in the collector. The collected oil is then filtered, and once the solvent is evaporated, leaving the oil in the pot as residue.

iv. The extract yield has been calculated by:

$$
\text { Oil yield }=\frac{\text { Amount of extracted oil }(\mathrm{g})}{\text { Amount of dry herbs and oil }(\mathrm{g})} \times 100 \%
$$

The second set of oil consisting of Aegle marmelos, curry leaves, and coconut oil mixture has been extracted in the same way. The extracted oil has been stored in a glass bottle until further analysis.

v. Preparation of nano-emulsion

The herbal oil and the surfactant were prepared in the following ratios 1:0.5, 1:1, 1:1.5, 1:2, 1:2.5. Nano-emulsions of these five ratios were prepared using a high-speed homogeniser (Tool-Tech), which mixes at 1000 to $5000 \mathrm{rpm}$. The homogenisation was carried out for one hour for each nano-emulsion and for all the ratios to obtain a stable and uniform nano-emulsion. The 10-, 20-, and 30-g-per-litre concentrations of nano-emulsions were characterised using particle size measurements. The emulsions have also been evaluated for their $\mathrm{pH}$ to determine their stability. As the level of surfactant increased, the 
particle size decreased, enabling it to penetrate the fabric more easily. Thermal stability was evaluated by maintaining the emulsions at varying temperatures, observing their homogenous nature, and recording any oil separation from the constituents. Visual methods (using a separating funnel) were used to observe the oil separation. The emulsion breaks and separates into immiscible compounds on reaching a particular temperature $\left(>60{ }^{\circ} \mathrm{C}\right.$ ). The stability of nano-emulsion 1 (combination of Moringa oleifera, curry leaves, and coconut oil) and nano-emulsion 2 (combination of Aegle marmelos, curry leaves, and coconut oil) was assessed and discussed later in Section 3.3. In this manner, emulsions have been characterised and optimised for the application of cotton fabrics. In the case of 1:1 ratio, $100 \mathrm{~mL}$ of distilled water, one $\mathrm{ml}$ of oil mixture (3 parts of Moringa oleifera, two parts of curry leaves, and one part coconut oil), and one $\mathrm{ml}$ of polysorbate 80 was used. This combination is termed as nano-emulsion 1. Similarly, for 1:1 ratio, Aegle marmelos was used in place of Moringa oleifera to produce nano-emulsion 2.

A particle size analyser (Shimadzu SALD- 7500 nano, Kyoto, Japan) was used for determining the particle size of the nano-emulsion of the herbal extracts. The Whiteness Index of the samples was measured using Spectra scan 5100+, Computer colour matching system (Rayscan, Liverpool, Australia). The test method uses the amount of light reflected from the fabric surface at each wavelength to give the Whiteness Index. A Meta-Lab MSI-17B (Meta-lab Scientific Industries, Mumbai, India) was used to measure the temperature stability of the emulsions at varying temperatures. The $\mathrm{pH}$ of nano-emulsions was calculated using a pH meter (EquipTronic) at room temperature $37^{\circ} \mathrm{C}$.

vi. Application on fabric:

The prepared nano-emulsions have been applied on organic cotton using two methods:

(i) Continuous process (Padding method): For organic cotton of both 20 and $60 \mathrm{~g} / \mathrm{m}^{2}$ fabrics, sample size $21 \mathrm{~cm} \times 30 \mathrm{~cm}$ was used. The fabric has been padded using a 2-dip and 2-nip method at 75\% expression (the rate at which fabrics passes through) of the padding mangle. The padded fabric is then dried at $80^{\circ} \mathrm{C}$ for five minutes and cured at $110^{\circ} \mathrm{C}$ for three minutes. Padding has been carried out for all the five ratios of nano-emulsion for both herbal oils.

(ii) Batch process (Exhaust method): The exhaust has been carried out using a Rota dryer machine. The fabric samples are kept in exhaustion at 1:50 LMR (liquid to material ratio) at $60{ }^{\circ} \mathrm{C}$ for one hour. The fabric after the exhaust method has been dried in air at room temperature. Exhaust has been carried out for all the five ratios of nano-emulsion for both the herbal oils.

\subsection{Fabric Characterisation}

Fabric surface morphology was examined using scanning electron microscopy (SEM) Carl Zeiss Supra 40 VP (Oberkochen, Germany), and samples were analysed under variable pressure conditions at a chamber pressure of $30 \mathrm{~Pa}$. A backscattered electron detector was used at an acceleration voltage of $20 \mathrm{kV}$ to obtain images of the samples. Low magnification images $(100 \times$ and $50 \times)$ were obtained at a working distance of approximately $25 \mathrm{~mm}$, whilst higher magnification images $(1000 \times)$ were obtained between 5 and $6 \mathrm{~mm}$. In addition, energy dispersive $\mathrm{X}$-ray spectroscopic analysis (EDX) was carried out using Apollo 40SDD (Tilburg, The Netherlands) and is used to determine the elemental composition of fabric treated with nano-emulsions. EDX analysis was performed using an acceleration voltage of $20 \mathrm{kV}$ and a working distance of approximately $15 \mathrm{~mm}$.

The chemical structure of finished and unfinished cotton fabric samples was characterised using Brucker Alpha II attenuated total internal reflectance-Fourier transform infrared spectroscopy (ATR-FTIR, Bruker Daltonik GmbH, Bremen, Germany). The FTIR spectra for cotton woven fabrics were recorded from 4000 to $600 \mathrm{~cm}^{-1}$. The resolution used is 4000 to 550 , made up of 32 scans. The internal reflection element of the ATR crystal was diamond. 


\subsection{Antimicrobial Tests}

Antimicrobial activity was evaluated by quantitative (AATCC 100:2019) and qualitative methods (AATCC 147:2016) [51,52]. Staphylococcus aureus strain No. ATCC 6538 (Gram-positive bacteria) and Escherichia coli strain No. ATCC 10,799 (Gram-negative bacteria) were used for this study. The controls used in the study are unfinished fabrics. The strains were cultured in nutrient agar and sterilised using an autoclave. The control and test samples were allowed in contact with bacteria for $24 \mathrm{~h}$, and the percentage reduction of micro-organisms was determined using the formula:

$$
\mathrm{R}=(\mathrm{B}-\mathrm{A} / \mathrm{B}) \times 100 \%
$$

where,

- A denotes the number of bacteria recovered from inoculated treated specimen after $24 \mathrm{~h}$;

- $\quad$ B denotes the number of bacteria recovered from the inoculated treated specimen immediately after inoculation, i.e., $0 \mathrm{~h}$.

In the parallel streak method, the test specimen (rectangular specimens cut 25-50 mm) and control sample is placed in contact with the nutrient agar for $24 \mathrm{~h}$. After incubation, a clear zone of inhibition in $\mathrm{mm}$ is calculated using the formula $\mathrm{W}=(\mathrm{T}-\mathrm{D}) / 2$, where $\mathrm{W}$ is the width of the clear zone of inhibition, $\mathrm{T}$ is the total diameter of the test specimen and clear zone in $\mathrm{mm}$, and $\mathrm{D}$ is the diameter of the test specimen. A zone of inhibition underneath and around the sample indicates antibacterial resistance. Antifungal tests were conducted using test strain Aspergillus niger (strain No. ATCC 6275) to evaluate the antifungal resistance of the finished samples. Samples were incubated for six days in the humidity chamber at $28{ }^{\circ} \mathrm{C}$ and $90 \%$ relative humidity (AATCC 30: III- 2013) [53].

Tensile strength was evaluated in warp and weft directions using ASTM D 5035-11 (2019) with a gauge length of $75 \mathrm{~mm}$ [54]. Wash tests were carried out in accordance with the ISO 2 procedure (IS 15370: 2005) [55]. A launderometer was used with a standard reference detergent (IEC), maintaining a wash temperature of $60^{\circ} \mathrm{C}$, using a material: liquid ratio of 1:50. This was followed by rinsing, washing and drying process. Air permeability was measured to determine the airflow perpendicular through the fabric using a Shirley Air Permeability tester with a pressure drop of $100 \mathrm{~Pa}(10 \mathrm{~mm}$ head of the water column) and with a surface test area of $5.0 \mathrm{~cm}^{2}$.

\section{Results and Discussions}

The selection of herbal combinations (Moringa oleifera, Aegle marmelos, curry leaf, coconut oil) was based on an extensive survey of herbal constituents, and the proportions of each constituent were based on several trials. As described in Section 2.2, fresh leaves of Moringa oleifera and Aegle marmelos were used to prepare different herbal extracts and to this extract, curry leaves and coconut oil were added to produce the two combinations-nano-emulsion 1 (Moringa oleifera, curry leaf and coconut oil) and nano-emulsion 2 (Aegle marmelos, curry leaf and coconut oil). The following section discusses the characterisation of herbal nanoemulsion, including particle size analysis, the thermal stability of herbal nano-emulsions, $\mathrm{pH}$ optimisation, determining the percentage add-on of nano-emulsions finish on to the organic cotton fabrics, and determination of Whiteness Index of finished organic cotton fabrics.

\subsection{Particle Size Analysis}

The particle size analysis study was carried out for "soon after preparation" and after one and two weeks to study the stability of nano-emulsions (Figure 3). The results indicated that the particle size decreases with the increase in the 'oil to surfactant' ratio. Nano-emulsion 2 had a marginal smaller nanoparticle size compared to nano-emulsion 1 . There is a shift in particle size observed for Moringa emulsions ranging from $210 \mathrm{~nm}$ 'soon after preparation' to $74 \mathrm{~nm}$ for the ratio 1:1 after two weeks. This was due to the active phytoconstituents action (the antioxidants present in both the herbs serve to reduce the particle size). The antioxidants 
are usually present as free radicals in the nano-emulsions and are unstable by nature. Thus, enabling the reduction of the particle size of the nano-emulsions.

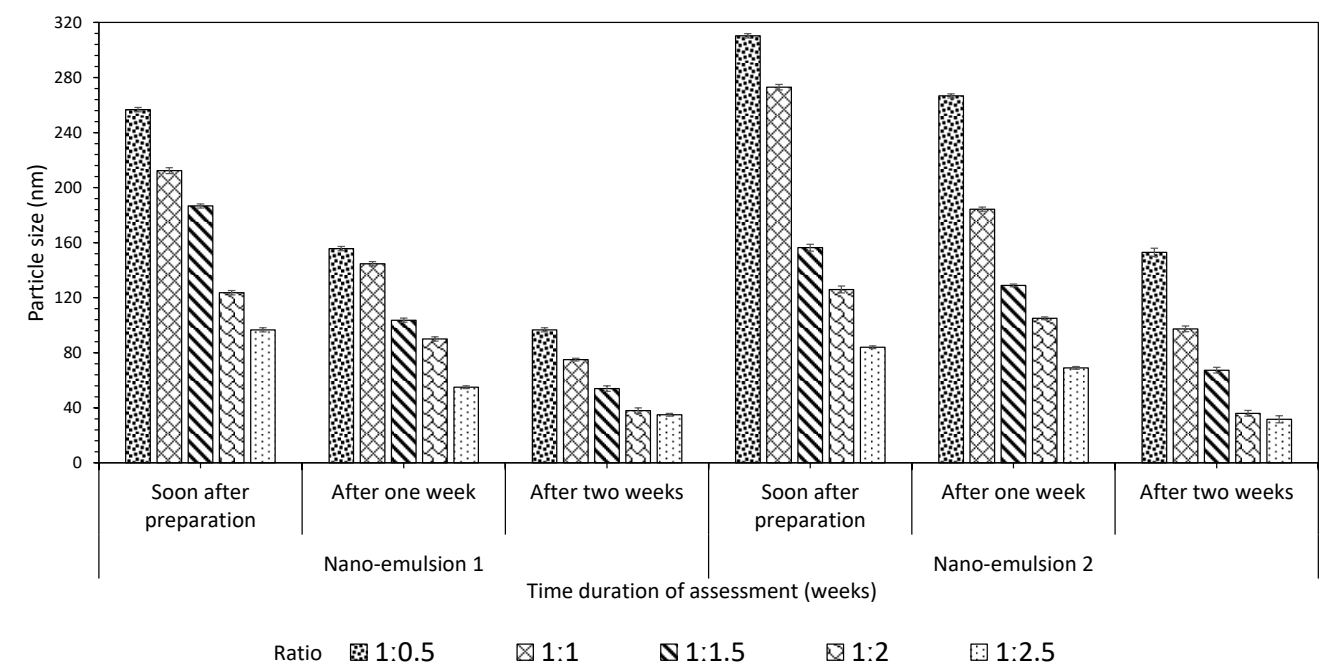

Figure 3. Particle size assessments.

Furthermore, the surfactant being proportionally more prominent than the oil and its interactions with the oil could undergo saponification with fatty acid molecules to form small micelles (aggregate of molecules). Hence, the surfactant, along with antioxidants, play a role in the reduction of particle size of the nano-emulsions. Besides, the presence of antioxidants gives better durability of the finish on the fabric since it prevents rancidity.

A similar trend was observed for nano-emulsion 2, where the particle size decreased from $273 \mathrm{~nm}$ soon after preparation to $98 \mathrm{~nm}$ after two weeks. It is worth mentioning that across all the ratios of both the nano-emulsions, the particle size decreased. For instance, for the 1:1 ratio, the particle size variation was $32 \%$ between soon after preparation and one week; after two weeks, there was a $65 \%$ variation in nanoparticle size. The particle size was prominent during the initial stages in the $100-250 \mathrm{~nm}$ region and $80-300 \mathrm{~nm}$ for nanoemulsion 1 and 2. In this study, the nano-emulsions were used after one week for treating the organic cotton, where the particle size was in the region 100-150 nm. Interestingly, the particle size of both the nano-emulsions after 60 weeks did not show any variation beyond 30-35 nm (data not presented here), showing excellent stability and shelf-life. Particle size analysis of hibiscus, curry leaf, and coconut oil-herbal extract combination was good in the various ratios, particularly for 90/10 (herbal oil/water), indicating good antimicrobial potential [56]. All the nano-emulsion ratios have been experimented with (1:0.5 to 1:2.5). After optimisation of the nano-emulsion, the 1:1 ratio was found to be appropriate and better than the other ratios, since the oil to surfactant ratio were in equal proportions. The surfactant proportion, when increased, gives the following properties, (1) the ease of penetration into the fabric; (2) particle size decreases; (3) good shelf-life; and (4) the ease of application using both methods (continuous and batch process) - the smaller the particle size, the better the penetration of nano-emulsion into the fabric.

\section{2. $p H$ Optimisation of Nano-Emulsions}

The optimisation of $\mathrm{pH}$ was carried out for the emulsions of all the herbal ratios. $0.1 \%$ sodium hydroxide and $0.1 \%$ hydrochloric acid solution was added to the emulsions to verify the stability of the nano-emulsion solution. From Figure 4, it can be observed that there is a gradual increase in $\mathrm{pH}$ value as the herbal ratio is varied from 1:0.5 to 1:2.5 and is applicable to both the nano-emulsions. For both the nano-emulsions 1 (Moringa oleifera) and nano-emulsions 2 (Aegle marmelos), the $\mathrm{pH}$ of the nano-emulsions was optimised between 5 and 6. 


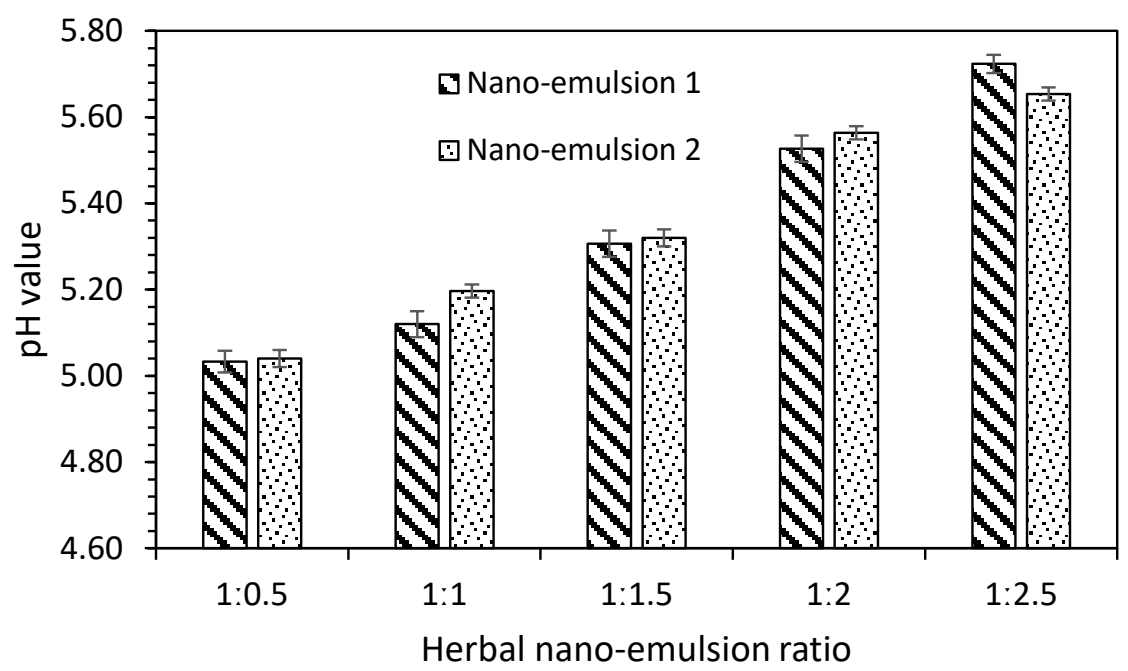

Figure 4. $\mathrm{pH}$ value of herbal nano-emulsions.

\subsection{Thermal Stability}

The thermal stability of the emulsions was carried out by keeping the emulsions in the water bath with a maximum temperature of $95^{\circ} \mathrm{C}$. It was observed that as the temperature of the mixture was increased to $60^{\circ} \mathrm{C}$, the emulsion was no longer stable, indicating the emulsion was stable only up to $60^{\circ} \mathrm{C}$. As the ratio (surfactant to oil) proportion increased, the thermal stability increased to $>60^{\circ} \mathrm{C}$. Thus, the thermal stability of nano-emulsions was monitored for three months, and it was stable up to $60^{\circ} \mathrm{C}$ throughout this period. However, any further increase in temperature above $60^{\circ} \mathrm{C}$ resulted in the breaking of emulsions (oil particles accumulated as a bottom layer). This was observed using a separating funnel. Therefore, nano-emulsion 1 was stable in the region $50-60{ }^{\circ} \mathrm{C}$, whilst nano-emulsion 2 was stable in the region $50-69^{\circ} \mathrm{C}$. The surfactant being a polysorbate reduces the surface tension of the nano-emulsion, increases the shelf life and the thermal stability, as already observed in Figure 5, for both the nano-emulsions. The surfactant-oil interaction is a continuous process of emulsification and saponification, thus reducing the particle size and lowering the surface tension.

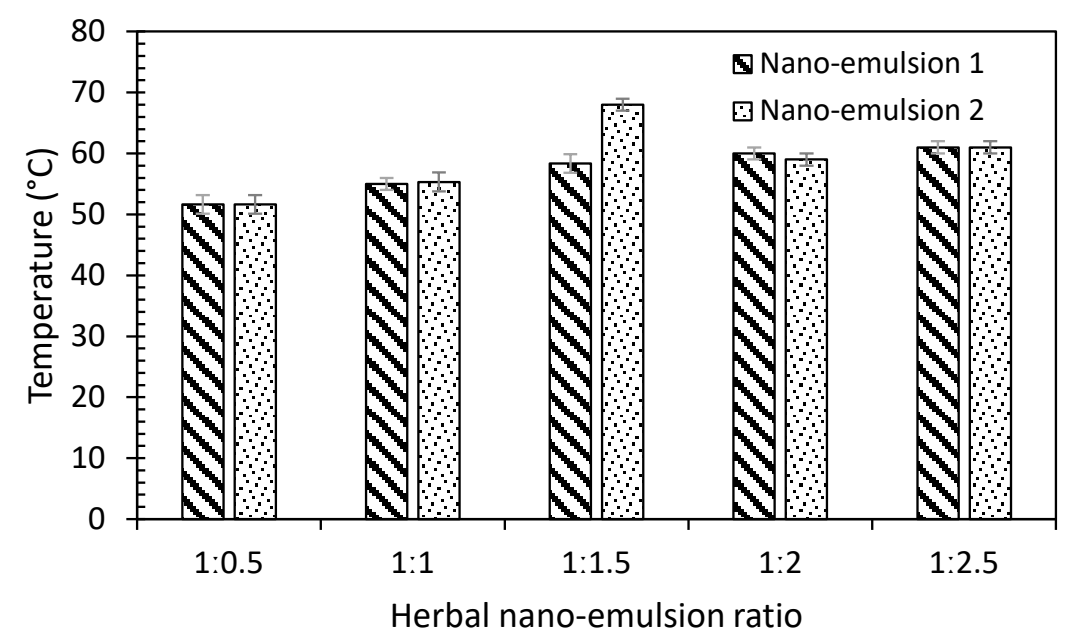

Figure 5. Thermal stability of herbal nano-emulsions.

\subsection{Nano-Emulsion Percentage Add-on}

The percentage add-on was evaluated for both the nano-emulsions finished fabrics as shown in Figure 6. $20 \mathrm{gsm}$ fabric had a higher add-on than $60 \mathrm{gsm}$ for all nano-emulsions and is explained as follows: (1) The structure of the $20 \mathrm{gsm}$ plain fabric was more open 
compared with the 60 gsm closely twill weave. The cover factor for 20 gsm in warp direction was 21 whilst for $60 \mathrm{gsm}$ was 63 , indicating that area covered by a set of threads in $60 \mathrm{gsm}$ was three times higher than $20 \mathrm{gsm}$, indicating a tightly woven packed structure of $60 \mathrm{gsm}$ than $20 \mathrm{gsm}$ fabric. (2) This was why $20 \mathrm{gsm}$ had a higher percentage add-on. In addition, it indicates the interaction between the nano-emulsion and the substrate. Had it been anything but mechanical adsorption, $60 \mathrm{gsm}$ would have shown a higher add-on than $20 \mathrm{gsm}$ because the surface area of $60 \mathrm{gsm}$ was higher than $20 \mathrm{gsm}$, as shown in Table 1. (3) Therefore, the interaction between the nano-emulsion and fabrics was simple mechanical adsorption subject to the voids present in the fabric structure. With a further increase in the area of the fabric, the percentage add-on remained unchanged, indicating that mechanical adsorption took place without any reaction between the nano-emulsions and fabric.

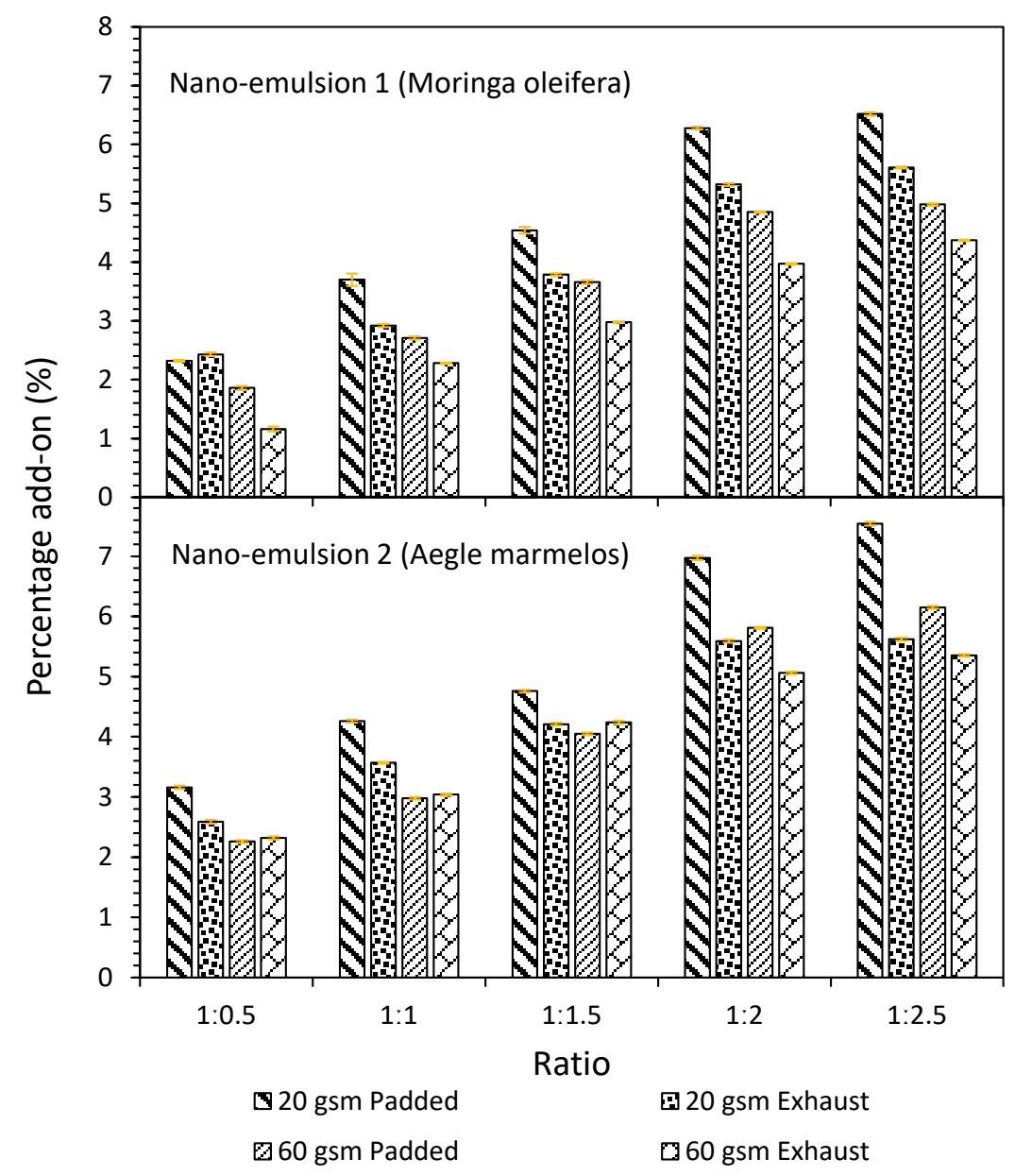

Figure 6. Percentage add-on of nano-emulsions.

Since the mechanism of finishing of fabrics with nano-emulsion is based on mechanical adsorption with no crosslinking, the type of fabric (weave) does not influence resultant properties, as it only depends only on the voids or interspaces present between the fibres/yarns within the fabric. Therefore, fabric weights chosen in this study was to determine the effect of finishing on different lightweight fabrics for its percentage add-on and durability of the finish (in different weave patterns). 
Table 1. Physical properties of fabrics.

\begin{tabular}{|c|c|c|c|}
\hline- & Fabric 1 & Fabric 2 & Notes \\
\hline Fabric weight $\left(\mathrm{g} / \mathrm{m}^{2}\right)$ & 20 & 60 & $\begin{array}{c}\text { GOTS }^{+} \text {certified } 100 \% \text { Organic } \\
\text { cotton fabric scoured and } \\
\text { bleached white }\end{array}$ \\
\hline Thickness (mm) & 0.2 & 0.5 & - \\
\hline Fabric structure & Plain weave $(1 / 1)$ & $\begin{array}{c}\text { Twill weave }(4 / 1) \text { warp } \\
\text { faced }\end{array}$ & $1.5 \mathrm{~m}$ width \\
\hline Fabric count EPI $\times \mathrm{CPI}$ & $75 \times 27$ & $117 \times 38$ & Ends per inch and picks per inch \\
\hline Warp yarn count (tex) & 8 & 29 & - \\
\hline Weft yarn count (tex) & 10 & 31 & - \\
\hline Cover factor $\mathrm{K}=\mathrm{k} 1$ (warp) $+\mathrm{k} 2$ (weft) & $21.2+64$ & $63+21$ & Area covered by a set of threads \\
\hline Air permeability (cc/s) & $>200$ & $63( \pm 2.73)$ & $\begin{array}{c}\text { The rate of airflow perpendicular } \\
\text { through the fabric }\end{array}$ \\
\hline $\begin{array}{l}\text { Tensile strength }(\mathrm{N}) \\
\text { Warp } \\
\text { Weft }\end{array}$ & $\begin{array}{l}322.39( \pm 11.01) \\
226.01( \pm 1.29)\end{array}$ & $\begin{array}{c}662.09( \pm 2.71) \\
287.84( \pm 12.76) \\
\end{array}$ & $\begin{array}{l}\text { Force required to break the fabric } \\
\text { under tension }\end{array}$ \\
\hline $\begin{array}{c}\text { Breaking extension }(\%) \\
\text { Warp } \\
\text { Weft }\end{array}$ & $\begin{array}{c}7.8( \pm 0) \\
27.53( \pm 0.26)\end{array}$ & $\begin{array}{l}15.68( \pm 0.14) \\
14.67( \pm 0.23)\end{array}$ & Extension at peak force \\
\hline
\end{tabular}

The number in brackets indicates the standard deviation. + GOTS-Global organic testing standards.

For the 1:2 ratio, a higher add-on percentage was observed for both the fabrics (20 and $60 \mathrm{gsm})$. This could be due to an increase in the surfactant to stabilise the herbal nanoemulsion and disperses into the fibre structure more uniformly. A similar pattern was also observed for nano-emulsion 2 in the continuous (padding method) as well as for the batch process (exhaust method). The 1:2 ratio had a better percentage add-on compared to other ratios. Overall, it can be inferred that the continuous (padded) process had a negligible higher difference than the batch process (exhaust). It is interesting to know that nanoemulsions ratio 1:0.5 to 1:2.5 showed a distinct change in percentage add-on on organic cotton fabrics. When comparing the nano-emulsions of both the herbs, the performance of Aegle marmelos was better than Moringa oleifera with respect to the preparation of nanoemulsions, the ease of finishing, and absorption higher percentage add-on. In the lower ratio (1:0.5), the surfactant is in a lower quantity, and will not have enough affinity to penetrate the fabric in the continuous method (padding), since the time of contact between the fabric and solution is lesser, whereas the time of contact is higher in the exhaust method. Hence, at a lower concentration of surfactant, there is a slight increase in the percentage add-on in the exhaust method compared with the padding method. As the surfactant concentration increases, the strike of the finish on cotton increases due to the lower surface tension of the emulsion. Hence, the padding method can adsorb more and increase the percentage add-on compared to the exhaust method.

The three replicates from the experiments showed a slight variation for different ratios for both the fabrics and nano-emulsions. Therefore, the error bars were low, as seen in Figure 6. In addition, the fabrics were finished in a single batch of $100 \mathrm{~m}$ length showing the uniform application of the percentage add-on, and the nano-emulsions prepared were consistent throughout this study. This could be the reason for the low variation in the samples.

\subsection{Whiteness Index}

The change in the Whiteness Index for nano-emulsion 1, 20 and 60 gsm fabrics increased as the herbal ratio varied from 1:0.5 to 1:2.5. Interestingly, the change in Whiteness Index for $20 \mathrm{gsm}$ fabric for nano-emulsion 1, particularly a 1:1 ratio, was approximately 
$12 \%$, whilst for 60 gsm fabric, this change was approximately $9.4 \%$. The change in the Whiteness Index was distinct for nano-emulsion 1 across all the ratios. In nano-emulsion 2, the change in the Whiteness Index increased marginally when the ratio varied from 1:0.5 to 1:2.5. However, at the 1:1 ratio, the change in the Whiteness Index for 20 and $60 \mathrm{gsm}$ was $7.8 \%$ and $6.1 \%$, respectively. This also reveals that the change in the Whiteness Index was well below $10 \%$ for nano-emulsion 2 compared with nano-emulsion 1 . The Whiteness Index for $20 \mathrm{gsm}$ fabric for both the nano-emulsions were marginally higher than $60 \mathrm{gsm}$ fabric. This was mainly due to the finer yarn linear density and open structure of the plain weave (20 gsm) than $60 \mathrm{gsm}$ fabric. The penetration of nano-emulsions was higher for $20 \mathrm{gsm}$ as the fabric structure was open, resulting in a distinct change in the Whiteness Index. The Whiteness Index above $10 \%$ is visually noticeable (to the naked eye) compared to Whiteness Index below $10 \%$, which is difficult to notice. This is shown in a blue dotted line, Figure 7.

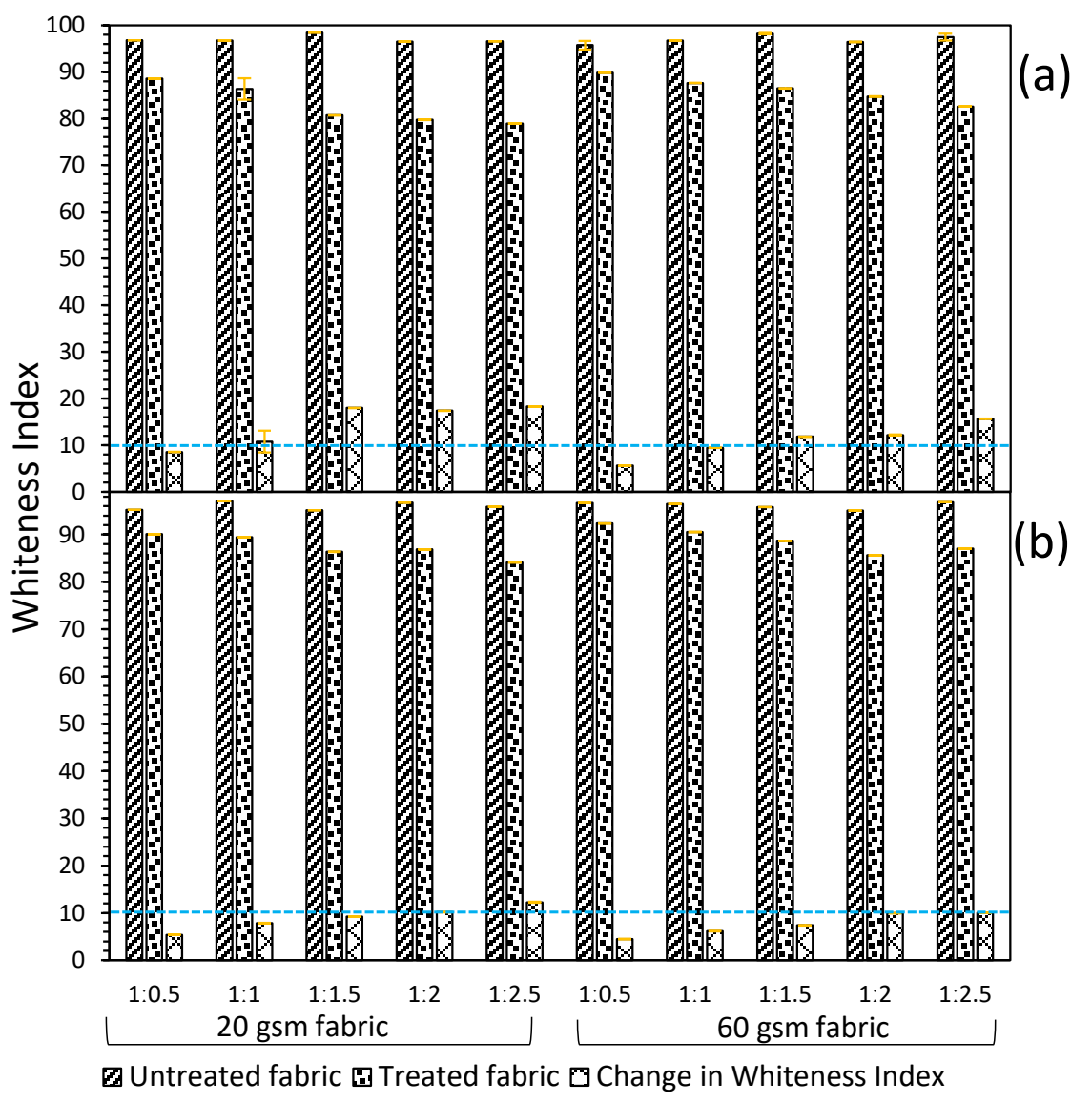

Figure 7. Whiteness Index for (a) Nano-emulsion 1 (Moringa oleifera); (b) Nano-emulsion 2 (Aegle marmelos) both 20 and 60 gsm organic cotton (dotted blue line indicates 10\% Whiteness Index that is noticeable)—padding method.

\subsection{Physical Properties}

The physical properties of both the 20 and $60 \mathrm{gsm}$ fabrics are presented in Table 1. It could be observed $20 \mathrm{gsm}$ fabric has a plain weave structure, whilst $60 \mathrm{gsm}$ fabric is a twill structure that has a marginally higher fabric count. Both the fabrics have a higher tensile strength in the warp direction compared to the weft direction, and this can be attributed to a higher number of warp yarns and finer yarn linear density. Organic cotton was scoured and bleached. These two fabrics were finished with two different nano-emulsions, 1 and 2, using continuous (padding) and batch methods (exhaust). 


\subsection{Antimicrobial Assessments \\ 3.7.1. Quantitative Tests}

The quantitative antimicrobial assessments reveal that both the herbal oil nanoemulsions have excellent resistance to Gram-positive and Gram-negative bacteria. The percentage reduction of micro-organisms ( $\mathrm{R} \%$ ) is shown in Table 2. For $20 \mathrm{gsm}$ for herbal nano-emulsion 1, the percentage reduction was in the range $98.44-99.30 \%$, and for nanoemulsion 2, the range was between $99.08 \%$ and $99.72 \%$. However, in $60 \mathrm{gsm}$ fabric, the range for nano-emulsion 1 and 2 was $99.02-99.29 \%$ and $99.74-99.87 \%$, respectively. Thus, the reduction of micro-organisms for $60 \mathrm{gsm}$ was marginally higher for nano-emulsion 2 than nano-emulsion 1 . This could also be attributed to the fabric structure of $60 \mathrm{gsm}$ fabric (twill weave) and fabric thickness, which had marginally higher pick-up of nano-emulsions, which offered higher resistance than 20 gsm plain-woven fabric.

Table 2. Reduction of micro-organisms (AATCC 100)—continuous process (padding method).

\begin{tabular}{|c|c|c|c|c|c|}
\hline \multirow{3}{*}{ Herbal Ratio } & \multirow{3}{*}{$\begin{array}{l}\text { Test } \\
\text { Culture }\end{array}$} & \multicolumn{4}{|c|}{$\begin{array}{l}\text { Reduction of Microorganisms (R) (\%) } \\
\text { Continuous Process (Padded) }\end{array}$} \\
\hline & & \multicolumn{2}{|c|}{ Moringa oleifera } & \multicolumn{2}{|c|}{ Aegle marmelos } \\
\hline & & $20 \mathrm{gsm}$ & $60 \mathrm{gsm}$ & $20 \mathrm{gsm}$ & $60 \mathrm{gsm}$ \\
\hline \multirow{2}{*}{ 1:0.5 } & S. aureus & 98.58 & 99.02 & 99.72 & 99.84 \\
\hline & E. coli & 98.46 & 99.03 & 99.70 & 99.82 \\
\hline \multirow{2}{*}{$1: 1$} & S. aureus & 98.44 & 98.55 & 99.81 & 99.81 \\
\hline & E. coli & 98.13 & 98.38 & 99.78 & 99.80 \\
\hline \multirow{2}{*}{ 1:1 After 10 washes } & S. aureus & 98.17 & 98.28 & 98.21 & 99.72 \\
\hline & E. coli & 97.79 & 98.14 & 98.09 & 99.66 \\
\hline \multirow{2}{*}{ 1:1 After 20 washes } & S. aureus & 97.34 & 97.41 & 97.70 & 99.26 \\
\hline & E. coli & 96.86 & 97.16 & 97.58 & 99.03 \\
\hline \multirow{2}{*}{$1: 1.5$} & S. aureus & 98.91 & 99.21 & 99.08 & 99.76 \\
\hline & E. coli & 98.84 & 99.15 & 99.16 & 99.72 \\
\hline \multirow{2}{*}{$1: 2$} & S. aureus & 98.82 & 98.80 & 99.25 & 99.77 \\
\hline & E. coli & 98.53 & 98.86 & 99.24 & 99.74 \\
\hline \multirow{2}{*}{$1: 2.5$} & S. aureus & 99.30 & 99.29 & 99.69 & 99.87 \\
\hline & E. coli & 99.05 & 99.07 & 99.70 & 99.76 \\
\hline
\end{tabular}

The standard deviation values for both the fabrics, nano-emulsions and for all ratios were negligible in the range 0.00006-0.00026; variations between the repeat samples were minimum.

The washing tests on the finished fabrics were carried out on the 1:1 ratio as a representative sample. 1:1 ratio (equal proportion of oil and surfactant) showed optimum values across a range of physical properties, and the results obtained from this ratio was representative of the remaining samples. Hence, the 1:1 ratio was chosen for evaluating the wash fastness after 10 and 20 wash cycles and antibacterial tests were reported. In the wash durability (padded method), after 10 and 20 washes for 20 gsm 1:1 ratio, there was a marginal decrease in the reduction of antimicrobial resistance compared to before wash, against $S$. aureus $0.27 \%$ and $1.1 \%$ respectively for nano-emulsion 1 . Similarly, for nanoemulsion 1, $20 \mathrm{gsm}$ fabric, there was a similar trend of marginal decrease in the reduction of antimicrobial resistance against $E$. coli ranging from $0.35 \%$ for ten washes to $1.29 \%$ for 20 washes. In the 20 gsm 1:1 ratio, after ten washes for nano-emulsion 2, the reduction of micro-organisms decreased to $1.57 \%$ against $S$. aureus, $1.69 \%$ E. coli compared to before wash. There was a further reduction in the antimicrobial resistance after 20 washes, $1.69 \%$ against $S$. aureus, $2.2 \%$ against $E$. coli.

For $60 \mathrm{gsm}$ fabric with nano-emulsion 1, a decrease in the antimicrobial resistance between before and after wash was observed, and these were marginal with $0.1 \%$ against S. aureus, $0.24 \%$ E. coli (10 washes) and $0.98 \%$ against S. aureus and $1.24 \%$ against E. coli 
(20 washes). For nano-emulsion 2 for both 10 and 20 washes, the decrease in the reduction of micro-organisms were less than 1\%. Hence, it can be inferred that $60 \mathrm{gsm}$ fabric outperformed $20 \mathrm{gsm}$ fabric with regard to antimicrobial resistance. In addition, the decrease in antimicrobial resistance after 20 wash cycles was minimum for both the fabrics and nano-emulsions, indicating that good finishing was achieved. The finishing of fabrics with nano-emulsions uniformly has a substantial effect on the overall antimicrobial resistance of fabrics. Recently, cotton fabrics were finished using Ocimum sanctum (Holy Basil or Tulsi) using the padding method with an average particle size of $33.2 \mathrm{~nm}$ and showed antimicrobial resistance to E. coli, S. aureus and antifungal resistance [40]. The authors reported that herbal nano-emulsions inhibited the growth of micro-organisms due to smaller size and uniform coating on the finished cotton fabrics, and good wash durability after 30 wash cycles [57].

The fabrics were also finished using the exhaust method (Table 3), and their antimicrobial resistance was evaluated for 1:1 and 1:2 ratios. It can be inferred that $60 \mathrm{gsm}$ fabric is marginally better than 20 gsm fabric against both the Gram-positive and Gram-negative bacteria. Wash tests also revealed there was a marginal drop in the reduction of microorganisms after 10 and 20 washes; however, the drop in the antimicrobial resistance was lower than the padded method, implying the exhaust method treated fabric has marginally better antimicrobial resistance compared to the padded treated fabric. Appendix A illustrates antimicrobial assessments (AATCC 100) for 20 and $60 \mathrm{gsm}$ fabrics taken at 0 and $24 \mathrm{~h}$.

Table 3. Reduction of micro-organisms (AATCC 100)—Batch process (exhaust method).

\begin{tabular}{|c|c|c|c|c|c|}
\hline \multirow{3}{*}{ Herbal Ratio } & \multirow{3}{*}{ Test Culture } & \multicolumn{4}{|c|}{ Reduction of Microorganism (R) \%-Exhaust Method } \\
\hline & & \multicolumn{2}{|c|}{ Moringa oleifera } & \multicolumn{2}{|c|}{ Aegle marmelos } \\
\hline & & $20 \mathrm{gsm}$ & $60 \mathrm{gsm}$ & $20 \mathrm{gsm}$ & $60 \mathrm{gsm}$ \\
\hline \multirow{2}{*}{$1: 1$} & S. aureus & 98.76 & 99.21 & 99.04 & 99.74 \\
\hline & E. coli & 98.60 & 99.28 & 99.13 & 99.69 \\
\hline \multirow{2}{*}{ 1:1 After 10 washes } & S. aureus & 98.39 & 99.09 & 98.67 & 99.18 \\
\hline & E. coli & 97.82 & 99.04 & 98.50 & 99.17 \\
\hline \multirow{2}{*}{ 1:1 After 20 washes } & S. aureus & 97.62 & 98.26 & 98.28 & 98.52 \\
\hline & E. coli & 97.57 & 98.15 & 97.70 & 98.26 \\
\hline \multirow{2}{*}{$1: 2$} & S. aureus & 99.43 & 99.12 & 99.27 & 99.78 \\
\hline & E. coli & 99.08 & 99.03 & 99.04 & 99.78 \\
\hline
\end{tabular}

Gas chromatography mass spectroscopy (GC-MS) and GC (gas chromatography) analysis will enable to identify the chemical compounds and phytoconstituents present in Moringa oleifera, Aegle marmelos, Murraya koengii (curry leaf), and coconut oil and is highlighted in Appendix A.1. All the above three herbal oils (Moringa oleifera, Aegle marmelos, curry leaf) contains oleic acid components (dodecanoic, tetradecanoic acid, hexadecenoic, octadecanoic acid and oleic acids, [58]. Coconut oil has 92\% saturated fatty acids [48,49]. GC-MS analysis of coconut oil revealed various fatty acids, among them capric acid, lauric acid, myristic acid and palmitic acid, were in high proportions. Thus, $C_{16}-C_{20}$ fatty acids found in these herbs and the phytoconstituents present demonstrated potential antibacterial and antifungal properties, as reported in previous research, Appendix A.1. These phytoconstituents, chemical compounds, and fatty acids inhibit the growth of bacteria, microbes, and fungi. Since the constituents of these three herbs are similar to each other (Appendix A.1), it offers a synergistic effect when blended and retaining the properties of each constituent. The antimicrobial values obtained on finishing cotton fabrics with the nano-emulsions 1 and 2 in this study justifies the above statement. 


\subsubsection{Qualitative Tests}

The antimicrobial assessments using the parallel streak method (AATCC 147:2016) are illustrated in Figure 8. For $20 \mathrm{gsm}$ fabric, there was no growth of bacteria below the fabric for both the nano-emulsions 1 and 2. However, for the $60 \mathrm{gsm}$ fabric, there was a clear zone of inhibition, and no growth below the fabric was observed. Furthermore, this inhibition zone was marginally higher against $S$. aureus nano-emulsion 2 than $E$. coli. This pattern was also noticed for nano-emulsion 1 , indicating that $60 \mathrm{gsm}$ fabric has better antimicrobial resistance for Gram-positive bacteria (S. aureus) than Gram-negative bacteria (E. coli).
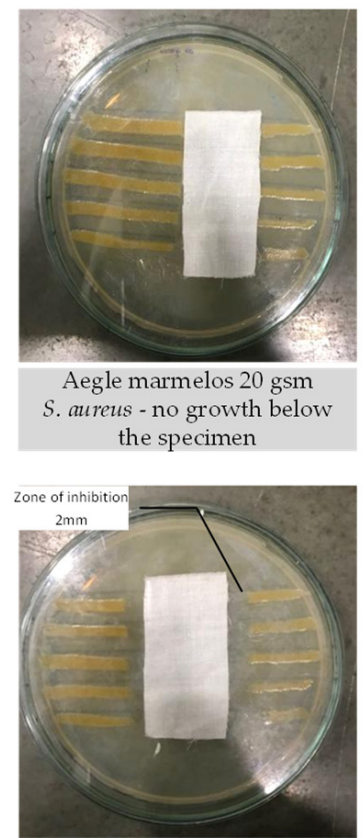

Aegle marmelos $60 \mathrm{gsm}$ S. aureus - no growth below the specimen
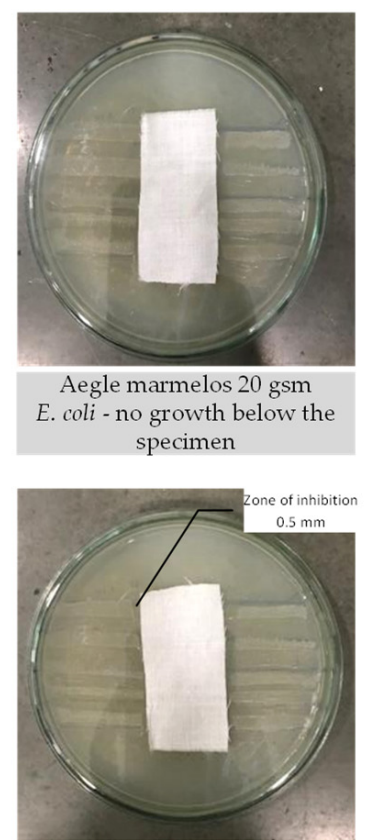

Aegle marmelos $60 \mathrm{gsm}$ E.coli - no growth below the specimen

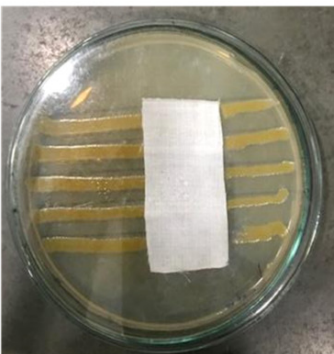

Moringa oleifera $20 \mathrm{gsm}$ S. aureus no growth below the specimen

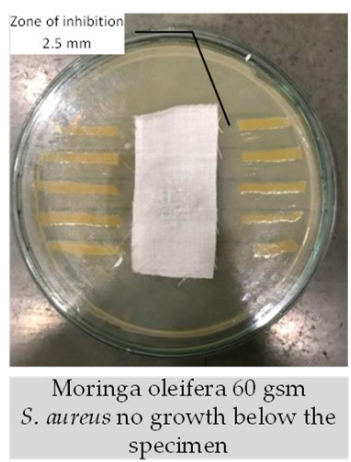

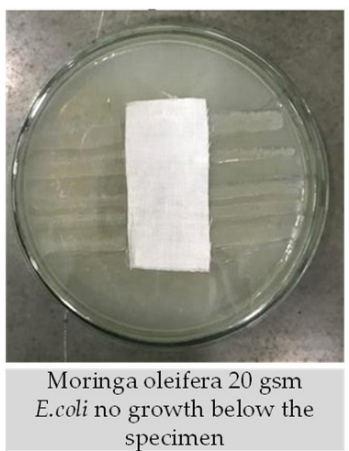

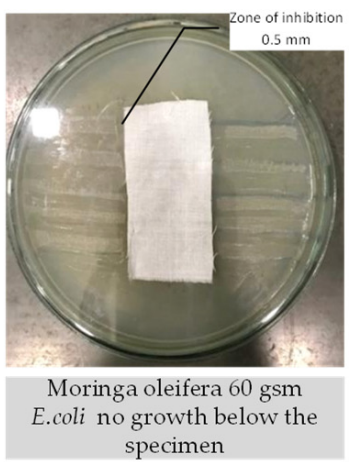

Figure 8. Antimicrobial tests AATCC 147:2016 parallel streak method.

\subsubsection{Antifungal Tests}

Fabrics treated with nano-emulsions 1 and 2 using the continuous (padding) method was presented here as a representative sample. For $60 \mathrm{gsm}$ fabric, there was no growth of fungi (Aspergillus niger), and a clear zone of inhibition was observed, $-42 \mathrm{~mm}$ for nanoemulsion 1 and $45 \mathrm{~mm}$ for nano-emulsion 2 . However, there was a 10\% growth of fungi for both the nano-emulsions 1 and 2 when using 20 gsm fabric (Table 4). These tests indicated that 60 gsm fabric showed excellent antifungal resistance for both the nano-emulsions. 
Table 4. Antifungal test AATCC 30-III 2013.

\begin{tabular}{|c|c|c|c|c|c|}
\hline \multirow{2}{*}{\multicolumn{2}{|c|}{ Sample Identification }} & \multirow{2}{*}{\multicolumn{2}{|c|}{$\begin{array}{c}\text { Zone of Inhibition } \\
\text { (Continuous Method) }\end{array}$}} & \multirow{4}{*}{ Rating * } & \multirow{4}{*}{ Interpretation } \\
\hline & & & & & \\
\hline & & \multirow[t]{2}{*}{ Moringa oleifera } & \multirow[t]{2}{*}{ Aegle marmelos } & & \\
\hline Fabric & Ratio & & & & \\
\hline $20 \mathrm{gsm}$ & $1: 1$ & No zone of inhibition & $\begin{array}{l}\text { No zone of } \\
\text { inhibition }\end{array}$ & 1 & $\begin{array}{c}\text { No zone of inhibition could be } \\
\text { seen around the fabric. There was } \\
\text { a trace of fungal growth on } \\
\text { the samples }\end{array}$ \\
\hline $60 \mathrm{gsm}$ & $1: 1$ & $42 \mathrm{~mm}$ & $45 \mathrm{~mm}$ & 0 & $\begin{array}{l}\text { A zone of inhibition can be seen. } \\
\text { Antifungal activity present }\end{array}$ \\
\hline
\end{tabular}

* Rating description: 0: no growth; 1: trace of growth (<10\%); 2: light growth (10-20\%); 3: medium growth (30-60\%) 4: and heavy growth ( $60 \%$ to complete coverage).

\subsection{ATR-FTIR Characterisation and SEM Analysis}

It can be observed from the FTIR, Figures 9 and 10, the functional groups of the cotton cellulose remain unaffected between treated and untreated fabrics. The peaks observed for 20 and 60 gsm are given below. FTIR analysis reveals that there was no chemical change in the structure of organic cotton, indicating that the herbal finishing of fabrics did not affect the cellulose polymer structure.
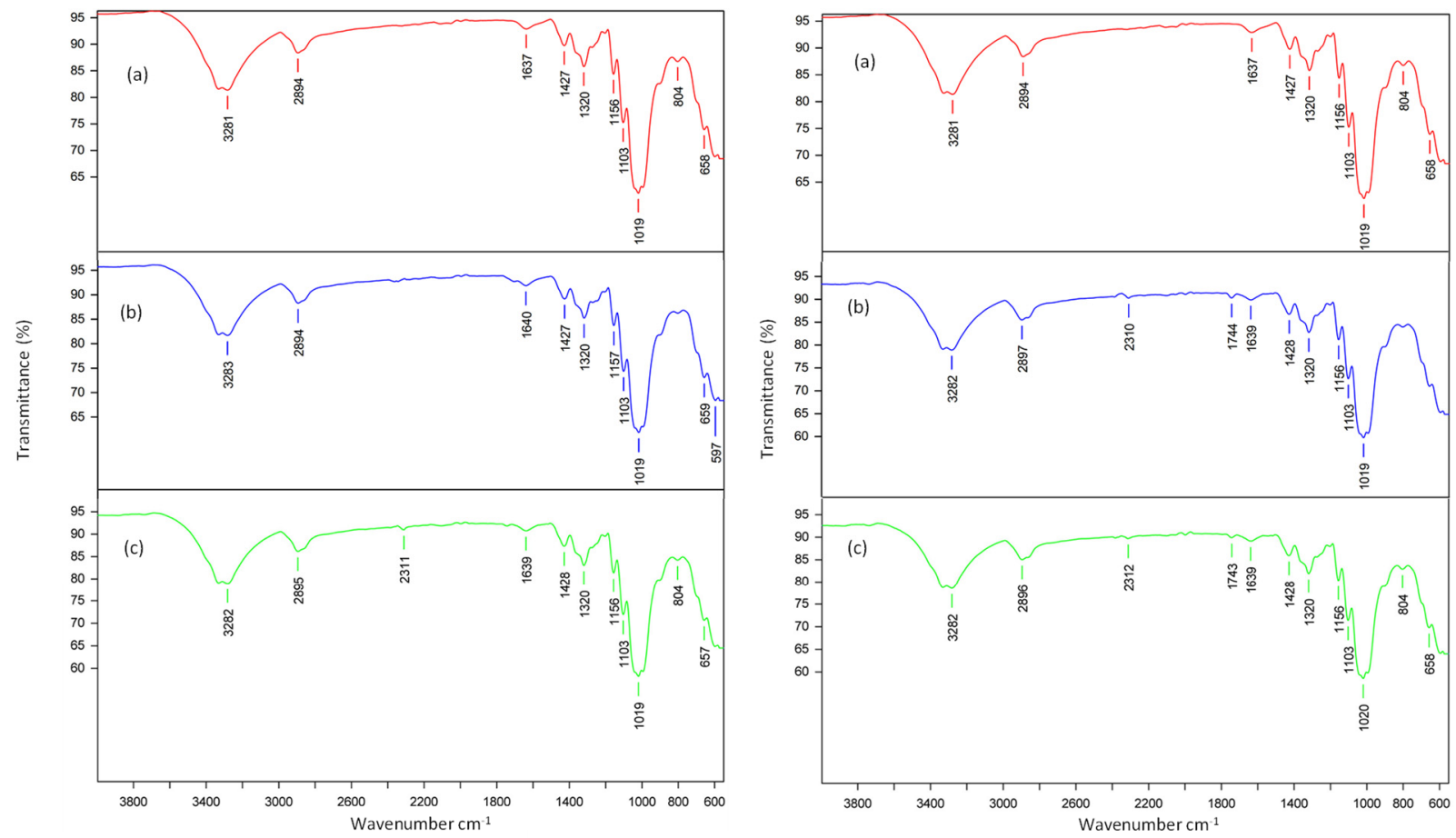

Moringa oleifera 1:1 $20 \mathrm{gsm}$ (a) control; (b) exhaust and (c) padding

Aegle marmelos 1:1 $20 \mathrm{gsm}$ (a) control; (b) exhaust and (c) padding

Figure 9. FTIR for Moringa oleifera and Aegle marmelos $20 \mathrm{gsm}$ fabrics. 

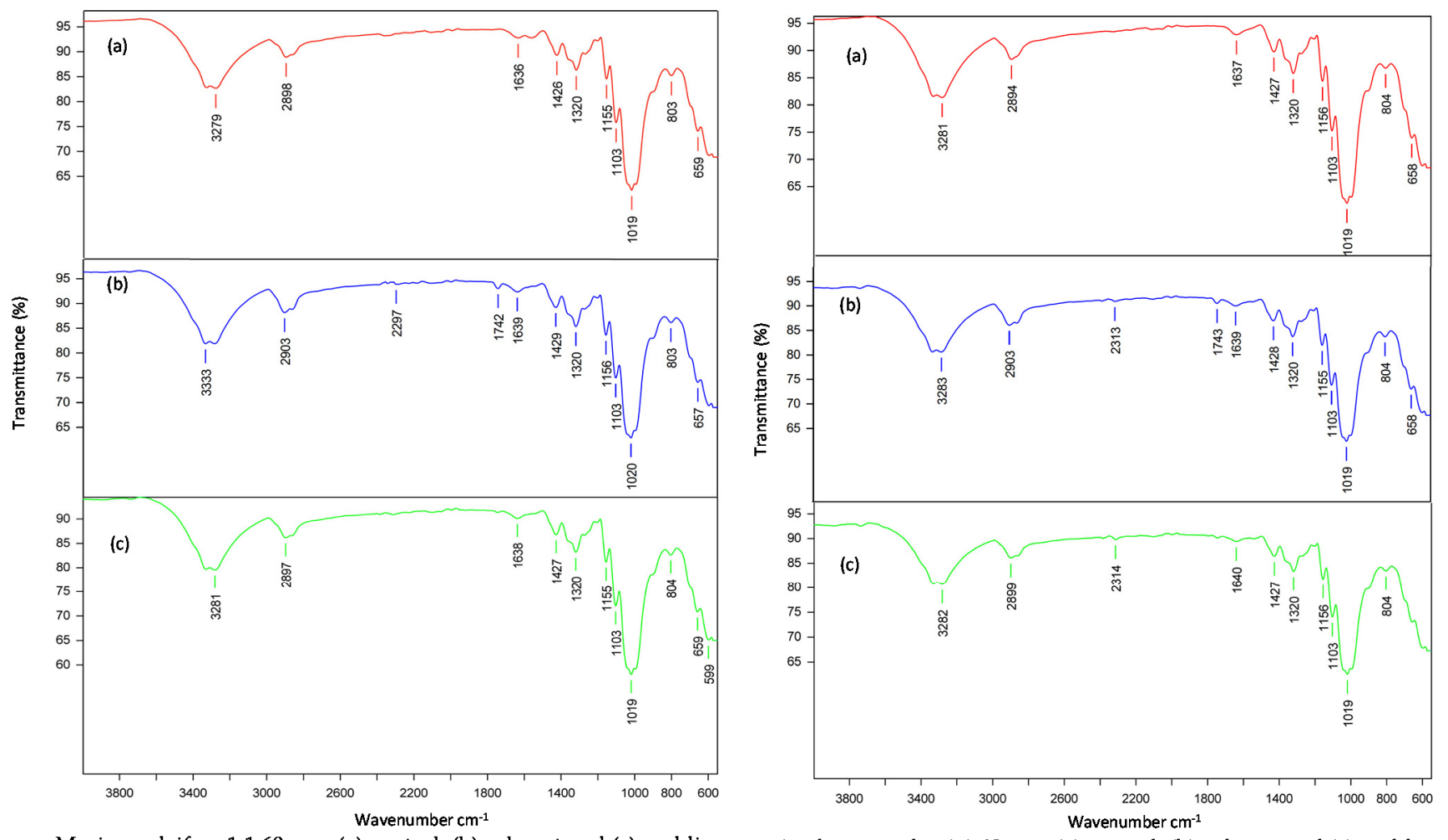

Moringa oleifera 1:1 $60 \mathrm{gsm}$ (a) control; (b) exhaust and (c) padding

Aegle marmelos 1:1 $60 \mathrm{gsm}$ (a) control; (b) exhaust and (c) padding

Figure 10. FTIR for Moringa oleifera and Aegle marmelos $60 \mathrm{gsm}$ fabrics.

In the case of control organic cotton fabric for $20 \mathrm{gsm}$, the spectra showing assignments at $3281 \mathrm{~cm}^{-1}$ relating to $\mathrm{O}-\mathrm{H}$ stretching (Carboxylic acid), $2894 \mathrm{~cm}^{-1} \mathrm{O}-\mathrm{H}$ stretching (alcohol), $1637 \mathrm{~cm}^{-1} \mathrm{C}-\mathrm{H}$ bending, $1427 \mathrm{~cm}^{-1} \mathrm{O}-\mathrm{H}$ bending, $1320 \mathrm{~cm}^{-1} \mathrm{O}-\mathrm{H}$ bending (phenol group), $1156 \mathrm{~cm}^{-1} \mathrm{C}-\mathrm{O}-\mathrm{C}$ stretching. In the case of $60 \mathrm{gsm}$ unfinished fabric, organic compounds present were identified as follows: $3279 \mathrm{~cm}^{-1} \mathrm{O}-\mathrm{H}$ stretch (alcohol), $2898 \mathrm{~cm}^{-1} \mathrm{~N}-\mathrm{H}$ amine salt, $1636 \mathrm{~cm}^{-1} \mathrm{C}=\mathrm{C}$ stretching, $1426 \mathrm{~cm}^{-1} \mathrm{O}-\mathrm{H}$ bending, $1320 \mathrm{~cm}^{-1}$ $\mathrm{O}-\mathrm{H}$ bending, $1155 \mathrm{~cm}^{-1} \mathrm{C}-\mathrm{O}$ stretching.

The organic compounds present in $20 \mathrm{gsm}$ fabric treated with (Moringa oleifera) nanoemulsion 1, by exhaust method as observed from Figure 9, assignments include $3283 \mathrm{~cm}^{-1}$ C-H stretching, $2894 \mathrm{~cm}^{-1} \mathrm{C}-\mathrm{H}$ stretching (alkane), $1640 \mathrm{~cm}^{-1} \mathrm{C}-\mathrm{N}$ stretching, $1427 \mathrm{~cm}^{-1}$ $\mathrm{O}-\mathrm{H}$ bending, $1157 \mathrm{~cm}^{-1} \mathrm{C}-\mathrm{O}-\mathrm{C}$ stretching, and $1103 \mathrm{~cm}^{-1} \mathrm{C}-\mathrm{N}$ stretching. While the fabrics finished by the continuous method for $20 \mathrm{gsm}$ consists of the following assignments $3282 \mathrm{~cm}^{-1} \mathrm{O}-\mathrm{H}$ stretching, $2895 \mathrm{~cm}^{-1} \mathrm{C}-\mathrm{H}$ stretching (alkane), $1639 \mathrm{~cm}^{-1} \mathrm{C}=\mathrm{C}$ stretching (alkene), and $1428 \mathrm{~cm}^{-1} \mathrm{O}-\mathrm{H}$ bending. The treated fabrics with nano-emulsion 1 showed spectra assignments similar to untreated fabrics.

Similarly, according to Figure 10, the organic compounds present in Moringa oleifera for $60 \mathrm{gsm}$ treated samples by exhaust method include $3333 \mathrm{~cm}^{-1} \mathrm{~N}-\mathrm{H}$ stretching, $2903 \mathrm{~cm}^{-1}$ $\mathrm{C}-\mathrm{H}$ stretching (alkane group), $1742 \mathrm{~cm}^{-1} \mathrm{C}=\mathrm{O}$ stretching (ester group), $1639 \mathrm{~cm}^{-1} \mathrm{C}=\mathrm{C}$ stretching (alkene), $1429 \mathrm{~cm}^{-1} \mathrm{O}-\mathrm{H}$ bending, $1320 \mathrm{~cm}^{-1} \mathrm{O}-\mathrm{H}$ bending (phenol), $1156 \mathrm{~cm}^{-1}$ $\mathrm{C}-\mathrm{O}-\mathrm{C}$ stretching, and $1103 \mathrm{~cm}^{-1}, \mathrm{C}-\mathrm{N}$ stretching. For $60 \mathrm{gsm}$ fabric using continuous process treatment, the spectra assignments include $3281 \mathrm{~cm}^{-1} \mathrm{O}-\mathrm{H}$ stretching, $2897 \mathrm{~cm}^{-1}$ $\mathrm{OH}$ stretch (alcohol), $1638 \mathrm{~cm}^{-1} \mathrm{C}=\mathrm{C}$ stretching, $1427 \mathrm{~cm}^{-1} \mathrm{O}-\mathrm{H}$ bending, $1320 \mathrm{~cm}^{-1} \mathrm{O}-\mathrm{H}$ bending, and $1103 \mathrm{~cm}^{-1} \mathrm{C}-\mathrm{N}$ stretching. It is observed from the FTIR analysis that there is an insignificant change in the peaks of ATR spectra of the finished fabric with the herbal oils as compared with the unfinished fabrics. This phenomenon was due to the simple mechanical adsorption of the oil in the voids of the fabric and held by Van der Waal forces. There is no chemical bond (ionic and covalent) formation between the fabric and oil. The nano-emulsions possess a high affinity toward the cotton fabric and penetrate easily into the voids of the fabric structure, and the steric hindrance of the oil molecule prevents 
it from leaving the fabric surface easily, resulting in good durability of the finish on the cotton fabric.

ATR spectra assignments for oil mixture 1 (Moringa oleifera) (Figure 11) include $2922 \mathrm{~cm}^{-1} \mathrm{O}-\mathrm{H}$ stretching; $1742 \mathrm{~cm}^{-1} \mathrm{C}-\mathrm{H}$ bending, and $1157 \mathrm{~cm}^{-1} \mathrm{C}-\mathrm{O}-\mathrm{C}$ stretching; however, for the cotton fabric ATR assignments include $3281 \mathrm{~cm}^{-1}$ relating to $\mathrm{O}-\mathrm{H}$ stretching (Carboxylic acid), $2894 \mathrm{~cm}^{-1} \mathrm{O}-\mathrm{H}$ stretching (alcohol), $1637 \mathrm{~cm}^{-1} \mathrm{C}-\mathrm{H}$ bending, $1427 \mathrm{~cm}^{-1} \mathrm{O}-\mathrm{H}$ bending, $1320 \mathrm{~cm}^{-1} \mathrm{O}-\mathrm{H}$ bending (phenol group) and $1157 \mathrm{~cm}^{-1} \mathrm{C}-\mathrm{O}-\mathrm{C}$ stretching. These ATR spectra for cotton fabrics are in line with the previously reported work [59]. The ATR spectra for the finished fabrics, as shown in Figure 9c, compared with the unfinished fabric Figure 9a, show insignificant changes in the peaks. However, it is observed that oil mixture 1 has a $\mathrm{C}-\mathrm{O}-\mathrm{C}$ stretching and $\mathrm{C}-\mathrm{H}$ bending, which were similar to the unfinished and finished cotton fabrics (Figure 11). There is an absence of characteristic peaks of the oil functional group due to the nanoparticle size of the oil mixture. Thus, confirming that there is no chemical interaction following the finishing of organic cotton fabrics with the herbal oil mixture. The above phenomenon was similarly observed for oil mixture 2 (Aegle marmelos) and for the finished cotton fabrics with oil mixture 2.

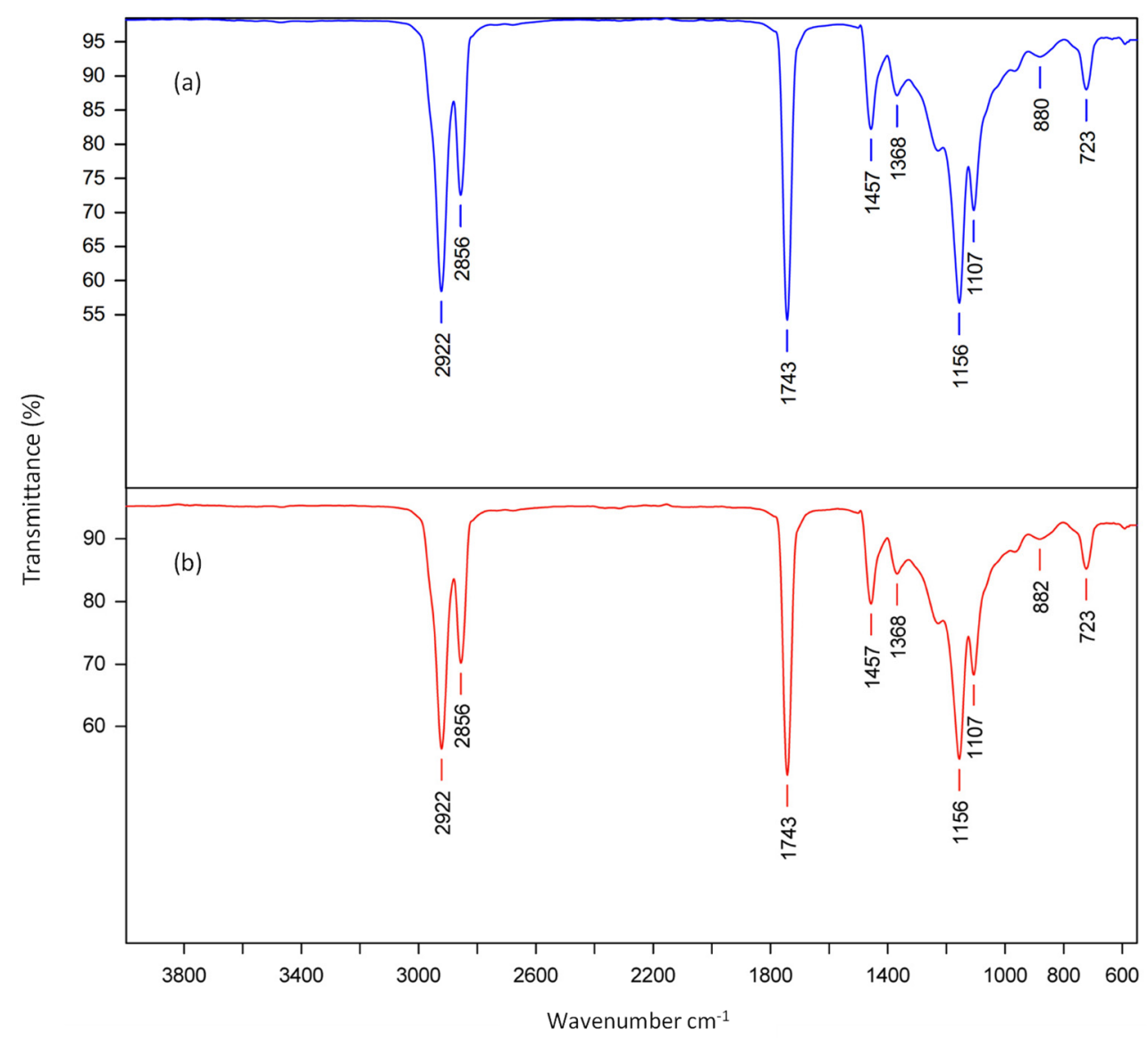

Figure 11. FTIR for (a) Moringa oleifera oil mixture and (b) Aegle marmelos oil mixture.

ATR spectra for herbal oil mixture 1 (Moringa oleifera, curry leaf and coconut oil) and mixture 2 (Aegle marmelos, curry leaf and coconut oil) the assignments were similar $\left(2922 \mathrm{~cm}^{-1}\right.$ $\mathrm{O}-\mathrm{H}$ stretching (alcohol); $1742 \mathrm{~cm}^{-1} \mathrm{C}-\mathrm{H}$ bending; and $1157 \mathrm{~cm}^{-1} \mathrm{C}-\mathrm{O}-\mathrm{H}$ stretching).

SEM analysis (Figure 12) for 20 and 60 gsm fabrics reveal that as the herbal ratio varied from 1:1 to 1:2.5 ratio, the ribbon-like shaped cotton fibres gradually flattened, and striations can be noticed on the fibre surface due to treatment with both the nano-emulsions. These visible changes in fibre morphology can be noticed for $60 \mathrm{gsm}$ fabrics and were marginally higher when treated with nano-emulsion 2. EDX analysis showed the presence of carbon elements for both the fabrics, indicating no other chemical constituents after 
treatment with both the nano-emulsions. However, there were minor traces of silicon and aluminium present, as shown in Figure 12. These elements arise during the processing of finishing fabrics with the nano-emulsions, where the nip rollers were coated with silicone rubber, and wet-pickup rollers were made of aluminium. This resulted in the samples showing traces of silicon and aluminium compounds, as seen in EDX analysis (Figure 12).
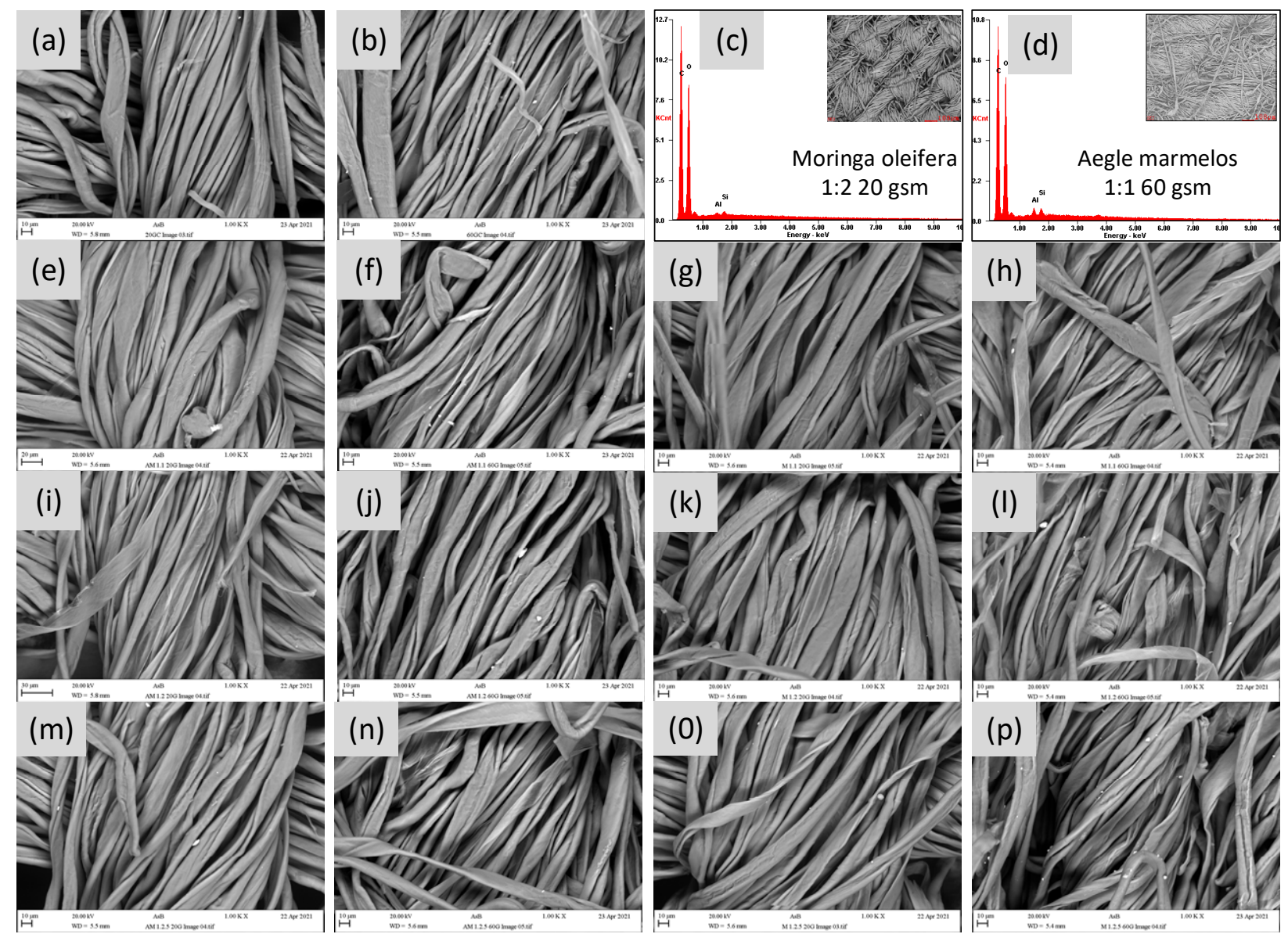

Figure 12. SEM of treated fabrics (padding method): (a) 20 gsm control fabric; (b) 60 gsm control fabric; (c) EDX analysis 1:2 nano-emulsion (Moringa oleifera) 20 gsm fabric; (d) EDX analysis 1:1 nano-emulsion 1 (Aegle marmelos) 60 gsm fabric; (e) 20 gsm treated with nano-emulsion 2, 1:1 ratio; (f) 60 gsm treated with nano-emulsion 2, 1:1 ratio; (g) 20 gsm treated with nano-emulsion 1, 1:1 ratio; (h) 60 gsm treated with nano-emulsion 1, 1:1 ratio; (i) 20 gsm treated with nano-emulsion 2, 1:2 ratio; (j) 60 gsm treated with nano-emulsion 2, 1:2 ratio; (k) 20 gsm treated with nano-emulsion 2, 1:2 ratio; (1) 60 gsm treated with nano-emulsion 1, 1:2 ratio; (m) 20 gsm treated with nano-emulsion 2, 1:2.5 ratio; (n) 60 gsm treated with nano-emulsion 2, 1:2.5 ratio; (o) 20 gsm treated with nano-emulsion 1, 1:2.5 ratio and (p) 60 gsm treated with nano-emulsion 1, 1:2.5 ratio.

\subsection{Tensile Strength}

Tensile strength of both the fabrics (20 and $60 \mathrm{gsm}$ ) decreased when the herbal ratio increased from 1:0.5 to 1:2 in warp and weft directions for both continuous and batch processes (Table 5). For $60 \mathrm{gsm}$ fabric, the tensile strength in the warp direction gradually decreased as the herbal ratio varied from 1:0.5 to 1:2 for both the nano-emulsions. However, with nano-emulsion 2, this decreases in tensile strength-warp and weft directions (for the continuous and batch process) were lower than finishing with nano-emulsion 1 . The cotton fabrics are made of $93 \%$ cellulose. Generally, there are two mechanisms by which cotton fabrics can be finished (1) forming a monolayer on the fabric surface; (2) crosslinking method. The herbal nano-emulsion used in this study has a hydrophobic nature and forms a monolayer of oil on the surface of the fabric without the crosslinking formation. The surface finishing of cotton fabric is due to the mechanical adsorption of nano-emulsions 
and depends on the pressure applied during the padding mangle process. The finishing of cotton fabrics with nano-emulsion neutralises the zeta potential on the surface of the fabric (being cationic in nature). This increases the penetration of the solution onto the fabric resulting in a minor reduction of tensile strength of fabrics. It is also worth highlighting that the $\mathrm{pH}$ of the nano-emulsions was 5.0-6.0 (acidic) and cotton is sensitive to acids, therefore affecting the tensile strength of both fabrics to an extent. However, it is worth mentioning that generally, the tensile strength of the fabric is affected during any finishing of textiles, and in this study, the overall strength of fabrics possesses sufficient strength. The breaking extension of the finished fabrics is shown in Appendix B.

Table 5. Tensile strength (N) Moringa oleifera.

\begin{tabular}{|c|c|c|c|c|c|c|c|c|}
\hline \multirow{2}{*}{$\mathbf{I}$} & \multicolumn{2}{|c|}{20 gsm Padding } & \multicolumn{2}{|c|}{60 gsm Padding } & \multicolumn{2}{|c|}{20 gsm Exhaust } & \multicolumn{2}{|c|}{60 gsm Exhaust } \\
\hline & Warp & Weft & Warp & Weft & Warp & Weft & Warp & Weft \\
\hline Control & $322.39 \pm 11.01$ & $226.01 \pm 1.29$ & $662.09 \pm 2.71$ & $287.84 \pm 12.76$ & $322.39 \pm 11.02$ & $226.01 \pm 1.29$ & $662.09 \pm 2.71$ & $287.84 \pm 2.76$ \\
\hline $1: 0.5$ ratio & $317.61 \pm 21.18$ & $220.59 \pm 2.77$ & $609.42 \pm 74.43$ & $265.35 \pm 15.85$ & $274.92 \pm 32.76$ & $198.37 \pm 7.25$ & $604.91 \pm 66$ & $254.26 \pm 2.68$ \\
\hline 1:1 ratio & $273.99 \pm 0.25$ & $217.25 \pm 4.38$ & $641.55 \pm 20.65$ & $266.18 \pm 9.83$ & $306.72 \pm 15.90$ & $224.2 \pm 1.17$ & $596.43 \pm 37.29$ & $231.01 \pm 5.33$ \\
\hline $1: 2$ ratio & $202.64 \pm 3.82$ & $195.14 \pm 7.41$ & $572.09 \pm 31.22$ & $225.61 \pm 5.23$ & $239.73 \pm 30.91$ & $189.33 \pm 32.22$ & $548.09 \pm 17.95$ & $267.32 \pm 2.96$ \\
\hline \multirow{2}{*}{ II } & \multicolumn{8}{|c|}{ Tensile Strength (N) Aegle marmelos } \\
\hline & \multicolumn{2}{|c|}{20 gsm Padding } & \multicolumn{2}{|c|}{60 gsm Padding } & \multicolumn{2}{|c|}{20 gsm Exhaust } & \multicolumn{2}{|c|}{60 gsm Exhaust } \\
\hline Control & $322.39 \pm 11.02$ & $226.01 \pm 1.29$ & $662.97 \pm 2.71$ & $287.85 \pm 12.76$ & $322.39 \pm 11.02$ & $226.92 \pm 1.29$ & $662.97 \pm 2.71$ & $287.85 \pm 12.76$ \\
\hline 1:0.5 ratio & $306.43 \pm 0$ & $177.56 \pm 0$ & $629.93 \pm 0$ & $255.85 \pm 0$ & $249.42 \pm 24.37$ & $217.59 \pm 23.33$ & $609.62 \pm 28.99$ & $243.6 \pm 19.03$ \\
\hline 1:1 ratio & $297.25 \pm 10.15$ & $211.51 \pm 11.86$ & $599.9 \pm 21.34$ & $248.65 \pm 9.53$ & $288.78 \pm 8.75$ & $206.66 \pm 7.0$ & $553.29 \pm 11.47$ & $243.8 \pm 8.06$ \\
\hline 1:2 ratio & $313.23 \pm 0$ & $207.16 \pm 0$ & $626.39 \pm 0$ & $275.12 \pm 0$ & $280.57 \pm 18.29$ & $212.63 \pm 8.89$ & $529.54 \pm 1.33$ & $215.85 \pm 6.58$ \\
\hline
\end{tabular}

\subsection{Air Permeability}

Air permeability was evaluated for both the fabrics 20 and $60 \mathrm{gsm}$, and it denotes the airflow perpendicular through the fabric, and it depends on the cover factor of fabric (area covered by a set of threads), fabric structure and fabric count (number of warp and weft yarns per unit area). The $60 \mathrm{gsm}$ fabric had a higher cover factor with a higher fabric count, providing resistance to airflow. Hence it can be observed that the rate of airflow was $60 \mathrm{cc} / \mathrm{s}$. The untreated $60 \mathrm{gsm}$ fabric had marginally higher air permeability $(63 \mathrm{cc} / \mathrm{s})$ than the fabrics treated with nano-emulsions 1 and 2 . However, in 20 gsm fabric, the fabric had a plain-woven structure and lower fabric count and cover factor than $60 \mathrm{gsm}$ fabric. As a result, the air permeability for $20 \mathrm{gsm}$ fabric was $>200 \mathrm{cc} / \mathrm{s}$ for both finished (nano-emulsions 1 and 2) and unfinished fabric.

\section{Conclusions}

The market potential for the use of antimicrobial textiles to improve hygiene would potentially grow and would reach USD 12.3 bn by 2024 at a compound annual growth rate (CAGR) 5.4\% between 2019 and 2024 [60]. In addition, the user awareness toward the preference of environmentally friendly antimicrobial hygiene textiles [61] is also expanding, indicating the focus toward improving hygiene in an environmentally friendly way. In this study, two organic cotton fabrics (20 and $60 \mathrm{gsm})$ were finished with two different herbal nano-emulsions-Moringa oleifera, coconut oil with curry leaf (nano-emulsion 1) and Aegle marmelos, coconut oil with curry leaf (nano-emulsion 2) at varying ratios using two different methods of finishing - continuous (padding) and batch process (exhaust). Results indicated that the organic cotton fabrics finished with two nano-emulsions had excellent antimicrobial efficacy against Gram-positive (S. aureus) and Gram-negative bacteria (E. coli) with good wash durability. For 60 gsm fabric, when finished with nano-emulsion 2, showed marginally higher antimicrobial resistance in the region $99.74-99.87 \%$ for varying herbal ratios than $20 \mathrm{gsm}$ fabrics. Wash tests of finished fabrics also showed good antimicrobial resistance; however, the reduction in micro-organisms dropped between $0.27-2.2 \%$ for 10 and 20 washes. The parallel streak method (AATCC 147) also revealed no growth of bacteria below the fabric, and a clear zone of inhibition for $60 \mathrm{gsm}$ fabrics was observed. In addition, the finished fabrics (60 gsm) showed a clear zone of inhibition in the range 
of $42-45 \mathrm{~mm}$ and with no growth of fungi (A. niger), demonstrating excellent antifungal efficacy. The particle size evaluations showed that herbal constituents were in the region of 55-150 nm and 70-266 nm for nano-emulsions 1 and 2, respectively. The nano-emulsions were stable and showed further reduction in particle size after two weeks. The percentage add-on for both the nano-emulsions increased with the increasing herbal ratio (1.0.5 to $1: 2.5)$, and the overall add-on for nano-emulsion 1 and 2 was $4-6 \%$ and 5-6\%, respectively, demonstrating good finishing of cotton fabrics. Optimisation of $\mathrm{pH}(5.0-6.0)$ and thermal stability of nano-emulsions $\left(50-60^{\circ} \mathrm{C}\right.$ ) showed good stability of both the nano-emulsions. Whiteness Index assessment showed that $20 \mathrm{gsm}$ fabric had an Index marginally above $10 \%$, whilst for $60 \mathrm{gsm}$ fabric, the index was well below $10 \%$ for both the nano-emulsions. An index below 10\% cannot be noticed in the naked eye. This shows that the finished fabrics with nano-emulsions were not affected from their original shade (bleached white), and the tonal changes were marginal.

FTIR analysis for finished and unfinished fabrics (20 and $60 \mathrm{gsm}$ ) revealed no chemical interaction on finishing of fabrics with herbal oil mixture, confirming that the finishing of fabrics was due to simple mechanical adsorption of herbal oil in the voids of the fabric structure. Furthermore, an insignificant change in the peaks of the ATR spectra between finished (20 and $60 \mathrm{gsm}$ ) and unfinished fabrics confirmed this phenomenon. When examining the tensile strength of both the fabrics and for nano-emulsions 1 and 2, the tensile strength in the warp direction was higher than the weft direction, and as the herbal ratio varied from 1:0.5 to 1:2.5, the tensile strength decreased when compared to unfinished fabric. The finished and unfinished fabrics were evaluated for air permeability, which showed no change in the rate of airflow (>200 cc/s) for $20 \mathrm{gsm}$; however, for $60 \mathrm{gsm}$ fabric, there was a marginal change in the rate of airflow $(60-65 \mathrm{cc} / \mathrm{s})$ across all the herbal ratios. These findings also showed that finished fabrics did not alter the fabric structure, allowing airflow through the fabric. SEM analysis also confirmed marginal variations in the fibre structure between finished and unfinished fabrics (20 and $60 \mathrm{gsm})$. It is also interesting to observe that the 1:1 herbal ratio for 20 and 60 gsm fabrics among various herbal ratios showed optimum results for percentage add-on, antimicrobial, antifungal efficacy, and good wash durability. Based on the above assessments, the 1:1 herbal ratio using continuous process (padding method) showed excellent results for both fabrics. This was also due to the mechanical adsorption of nano-emulsions onto the fabric surface.

Both the herbal combinations studied in this research (Moringa oleifera and Aegle marmelos) have demonstrated excellent antimicrobial resistance. Generally, Moringa oleifera is widely preferred for skin ailments and other diseases, which was reported by previous studies $[62,63]$ and methanol extracts of Moringa oleifera show resistance to a wide range of bacterial strains [64]. This also indicates the potential of these herbs to develop further innovative combinations to treat various diseases and ailments. This research adds to the literature by demonstrating a novel method of preparing nano-emulsions using a combination of herbs and finishing them on organic cotton fabrics. This method of finishing fabrics with all-natural herbal nano-emulsion to develop antimicrobial finishes on cotton fabrics can be widely used for healthcare and hygiene textiles. The herbal finishes also possess low adverse effects compared to synthetic compounds and are environmentally friendly. The study can be further developed with varying concentrations of herbal nanoemulsions on different fabrics and understand the mechanism of processing for the desired end-use.

Author Contributions: Conceptualisation-U.S. and P.D.V.; methodology-U.S.; P.D.V., S.P., and S.K.; data collection and preparation-S.K. and S.P.; investigation-U.S., P.D.V., S.P., and S.K.; formal analysis-P.D.V., S.K., and S.P; writing — original draft preparation-P.D.V. and U.S.; writing-review and editing-P.D.V., U.S., S.P., and S.K.; supervision-U.S.; project administration-U.S. and P.D.V.; funding acquisition-P.D.V. and U.S. All authors have read and agreed to the published version of the manuscript. 
Funding: This research received internal funding-Global Challenges Research Fund (GCRF) through Manchester School of Art and Research Centre, Faculty of Arts and Humanities, Manchester Metropolitan University, UK Project ID: 328682.

Institutional Review Board Statement: Not applicable.

Informed Consent Statement: Not applicable.

Data Availability Statement: The data presented in this study are available on request from the corresponding author.

Acknowledgments: The authors would like to acknowledge the kind contribution from the following technical/support colleagues: Hayley Andrews, MMU, UK., Scanning Electron Microscopy, EDX analysis; Derek Hebdon-Textile testing, MMU, UK.; all staff of the Department of Fibres and Textile Processing Technology, ICT, Mumbai.; Mrinal Choudhary, WRA (Wool Research organisation), Smita Bhatt and Seema Patel and Madhura Nerurkar, Calantha Biotech, Mumbai India; and V. Dhanapal, India, for providing support toward development 3D images.

Conflicts of Interest: The authors declare no conflict of interest.

\section{Appendix A.}

Antimicrobial Tests (AATCC 100) for 20 and 60 gsm Fabrics.
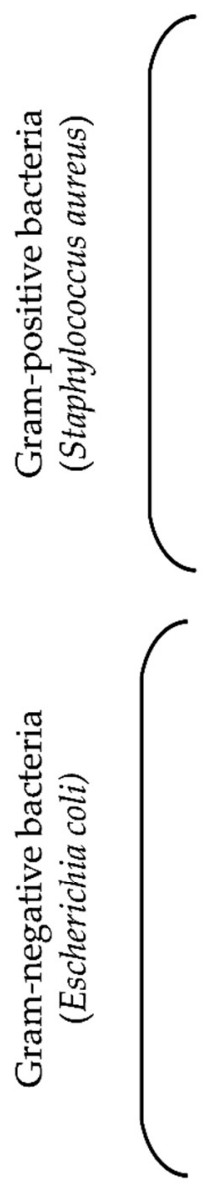

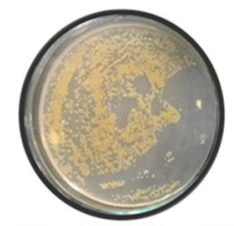

(a) $20 \mathrm{gsm} 1: 10 \mathrm{~h}$

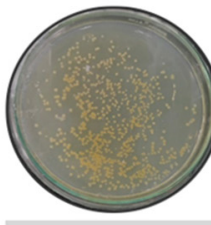

(e) $60 \mathrm{gsm} 1: 10 \mathrm{~h}$

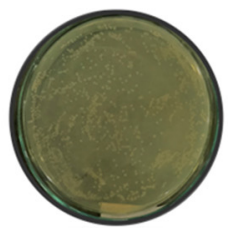

(i) $20 \mathrm{gsm} 1: 10 \mathrm{~h}$

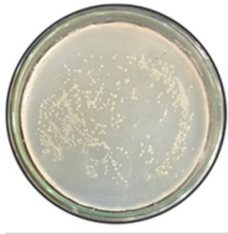

(m) $60 \mathrm{gsm} 1: 10 \mathrm{~h}$

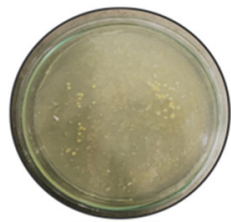

(b) $20 \mathrm{gsm} 1: 124 \mathrm{~h}$
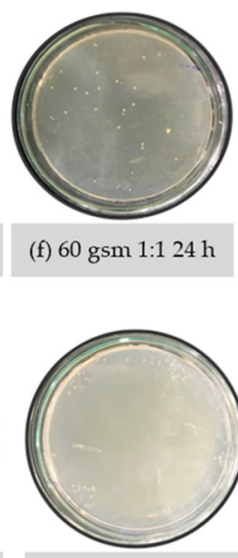

(j) $20 \operatorname{gsm} 1: 124 \mathrm{~h}$

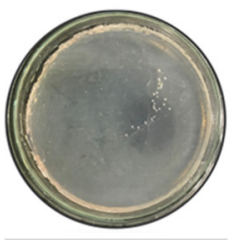

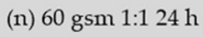

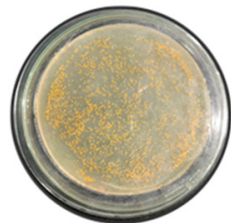

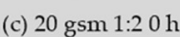

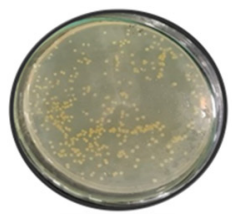

(g) $60 \mathrm{gsm} 1: 20 \mathrm{~h}$

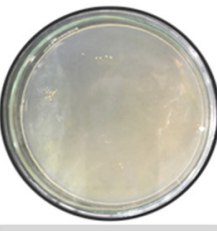

(d) $20 \mathrm{gsm} \mathrm{1:20 \textrm {h }}$

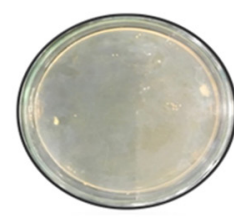

(h) $60 \mathrm{gsm} 1: 224 \mathrm{~h}$

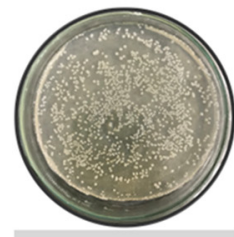

(k) $20 \mathrm{gsm} 1: 20 \mathrm{~h}$

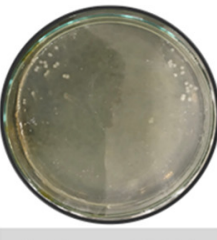

(1) $20 \mathrm{gsm} 1: 224 \mathrm{~h}$

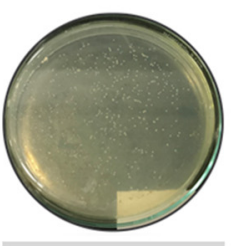

(o) $60 \mathrm{gsm} \mathrm{1:20 \textrm {h }}$

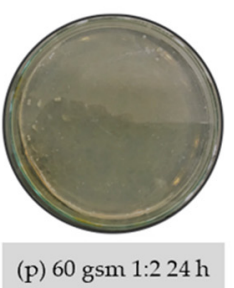

Appendix A Antimicrobial Tests (AATCC 100) for 20 and $60 \mathrm{gsm}$ Fabrics (Moringa oleifera) 


\section{Appendix A.1. GC-MS Analysis}

Chemical Constituents, Phytoconstituents and Compounds and Present in Moringa oleifera, Aegle marmelos, and Murraya koengii (curry leaf), and Coconut oil Using GCMS Analysis.

Appendix A.1.1. Moringa oleifera

GC-MS analysis of Moringa oleifera showed sixteen chemical compounds from the leaf methanolic extract and they are as follows: 9-octadecenoic acid (20.89\%), L-(+)-ascorbic acid2,6- dihexadecanoate (19.66\%), 14-methyl-8-hexadecenal (8.11\%), 4- hydroxyl-4-methyl-2pentanone $(7.01 \%)$, 3-ethyl-2, 4-dimethylpentane $(6.14 \%)$, phytol $(4.24 \%)$, octadecamethylcyclononasiloxane $(1.23 \%), 1$, 2-benzene dicarboxylic acid (2.46\%), 3, 4-epoxyethanone comprising $(1.78 \%)$, N-(-1-methylethyllidene)-benzene ethanamine $(1.54 \%), 4,8,12,16$ tetramethylheptadecan-4-olide (2.77\%), 3-5-bis (1, 1-dimethylethyl)-phenol $(2.55 \%), 1$ hexadecanol $(1.23 \%), 3,7,11,15$-tetramethyl-2 hexadecene-1-ol (1.17\%), hexadecanoic acid $(2.03 \%)$ and 1, 2, 3-propanetriyl ester-9 octadecenoic acid (1.23\%), [58].

Five chemical constituents were identified in methanolic seed extract, and they are oleic acid (84\%), L-(+)-ascorbic acid- 2, 6-dihexadecanoate (9.80\%), 9-octadecenoic acid $(1.88 \%)$, methyl ester-hexadecanoic acid $(1.31 \%)$ and 9-octadecenamide $(0.78 \%)$. These chemical constituents and bioactive compounds present in Moringa oleifera confirmed the medicinal values [58].

In addition, different types of active phytoconstituents like alkaloids, protein, quinine, saponins, flavonoids, tannin, steroids, glycosides, fixed oil and fats were present in Moringa oleifera. Furthermore, various other constituents were also present niazinin A, niazinin B and niazimicin A, niaziminin B [48]. Leaf extracts of Moringa oleifera were reported to inhibit the growth of Pseudomonas aeruginosa and Staphylococcus aureus [65]. These phytoconstituents and compounds enable the inhibition of microbial growth.

\section{Appendix A.1.2. Aegle marmelos}

GC-MS analysis of Aegle marmelos using methanolic extracts revealed twenty compounds of which Stigmasterol $(14.49 \%)$, hexadecenoic acid $(13.20 \%)$ and tetradecanoic acid $(2.35 \%)$ were identified. These are fatty acids and provide antimicrobial resistance. The leaf extracts with methanol solvents showed high antimicrobial activity against Escherichia coli, Klebsiella sp. Enterococcus sp, and Proteus mirabilis [49].

\section{Appendix A.1.3. Murraya koengii (Curry Leaf)}

Curry leaf is widely consumed in Indian cuisine for its distinct aroma and medicinal value and used as in ayurvedic medicine for treating a variety of diseases [66]. GC-MS chromatogram of the methanolic extract of Murraya koenjii showed five compounds: $\alpha$.Caryophyllene, 2-phenyl-4-quinolinecarboxamide, Phenanthrene, 10H-Phenoxaphosphine, and 1,5-Diformyl-2,6-Dimethoxy-Anthracene [66]. These components enable antimicrobial resistance.

\section{Appendix A.1.4. Coconut oil}

Coconut oil is extracted from the dried kernel of the coconuts, widely grown in tropical countries, produces a mild yellow colour oil with $92 \%$ saturated fatty acids $[50,67]$. It is a vegetable oil with a high percentage of fatty acid (lauric acid $48.3 \%$ and $18.4 \%$ myristic acid) [68]. GC-MS analysis of coconut oil revealed various fatty acids, among them capric acid, lauric acid, myristic acid and palmitic acid, were in high proportions. It is worth mentioning that from the analysis that coconut oil has higher saturated fatty acid $(87.2 \%)$ and lower unsaturated fatty acid $(8.4 \%)$, which is mainly composed of oleic acid (5.5\%) [68]. Saturated fatty acids have health benefits, including being antimicrobial and increasing body immunity [67]. Both lauric acid [69] and oleic acid [70] have many health benefits. Lauric acid derived from coconut oil has shown resistance to a wide range 
of Gram-positive and Gram-negative bacteria [69]. Monolaurin is an antimicrobial agent derived from lauric acid and glycerin [71]. Lauric acid is associated with treating a range of skin conditions-acne, [72] and psoriasis [73].

\section{Appendix B.}

Tensile strength elongation.

Table A1. Tensile strength-elongation values for 20 and $60 \mathrm{gsm}$ fabrics treated with nano-emulsion 1 and 2 from padded and exhaust method.

\begin{tabular}{|c|c|c|c|c|c|c|c|c|}
\hline \multirow{3}{*}{ I } & \multicolumn{8}{|c|}{ Breaking Extension (\%) Moringa oleifera } \\
\hline & \multicolumn{2}{|c|}{20 gsm Padding } & \multicolumn{2}{|c|}{60 gsm Padding } & \multicolumn{2}{|c|}{20 gsm Exhaust } & \multicolumn{2}{|c|}{60 gsm Exhaust } \\
\hline & Warp & Weft & Warp & Weft & Warp & Weft & Warp & Weft \\
\hline Control & $7.81 \pm 0.00$ & $27.33 \pm 0.26$ & $15.68 \pm 0.14$ & $14.675 \pm 0.23$ & $7.81 \pm 0.00$ & $27.325 \pm 0.26$ & $15.68 \pm 0.14$ & $14.68 \pm 0.23$ \\
\hline 1:0.5 ratio & $8.03 \pm 0.21$ & $29.25 \pm 0.16$ & $16.31 \pm 0.24$ & $12.51 \pm 0.00$ & $7.19 \pm 0.49$ & $26.23 \pm 1.86$ & $18.51 \pm 1.09$ & $15.31 \pm 0.18$ \\
\hline $1: 1$ ratio & $8.18 \pm 0.00$ & $26.34 \pm 1.70$ & $17.5 \pm 0.97$ & $12.49 \pm 0.49$ & $7.68 \pm 0.09$ & $27.71 \pm 0.42$ & $18.68 \pm 0.52$ & $11.71 \pm 1.70$ \\
\hline $1: 2$ ratio & $29.18 \pm 1.15$ & $20.41 \pm 0.54$ & $15.01 \pm 1.34$ & $11.33 \pm 0.85$ & $8.57 \pm 1.49$ & $25.51 \pm 5.28$ & $18.00 \pm 0.64$ & $13.55 \pm 1.27$ \\
\hline \multirow{2}{*}{ II } & \multicolumn{8}{|c|}{ Breaking Extension (\%) Aegle marmelos } \\
\hline & \multicolumn{2}{|c|}{20 gsm Padding } & \multicolumn{2}{|c|}{60 gsm Padding } & \multicolumn{2}{|c|}{20 gsm Exhaust } & \multicolumn{2}{|c|}{60 gsm Exhaust } \\
\hline Control & $7.81 \pm 0.00$ & $27.33 \pm 0.26$ & $15.68 \pm 0.14$ & $14.68 \pm 0.23$ & $7.81 \pm 0.00$ & $27.33 \pm 0.26$ & $15.68 \pm 0.14$ & $14.68 \pm 0.23$ \\
\hline 1:0.5 ratio & $7.94 \pm 0.00$ & $20.82 \pm 0.00$ & $14.44 \pm 0.00$ & $13.02 \pm 0.00$ & $6.07 \pm 0.72$ & $23.70 \pm 0.23$ & $15.23 \pm 0.25$ & $14.33 \pm 0.06$ \\
\hline 1:1 ratio & $6.62 \pm 0.47$ & $24.07 \pm 0.72$ & $17.78 \pm 0.03$ & $12.57 \pm 0.26$ & $8.08 \pm 0.76$ & $23.71 \pm 0.69$ & $15.44 \pm 0.06$ & $14.45 \pm 0.11$ \\
\hline $1: 2$ ratio & $8.34 \pm 0.00$ & $21.83 \pm 0.00$ & $17.73 \pm 0.00$ & $13.22 \pm 0.00$ & $7.45 \pm 0.26$ & $27.80 \pm 3.12$ & $15.75 \pm 0.07$ & $14.11 \pm 0.02$ \\
\hline
\end{tabular}

\section{References}

1. Lim, S.; Hudson, S. Application of a fiber-reactive chitosan derivative to cotton fabric as an antimicrobial textile finish. Carbohydr. Polym. 2004, 56, 227-234. [CrossRef]

2. Neely, A.; Maley, M.P. Survival of enterococci and staphylococci on hospital fabrics and plastics. J. Clin. Microbiol. 2000, 38, 724-726. [CrossRef] [PubMed]

3. Mitchell, A.; Spencer, M.; Edmiston, C. Role of healthcare apparel and other healthcare textiles in the transmission of pathogens: A review of the literature. J. Hosp. Infect. 2015, 90, 285-292. [CrossRef] [PubMed]

4. Morais, D.S.; Guedes, R.M.; Lopes, M.A. Antimicrobial approaches for textiles: From research to market. Materials 2016, 9, 498. [CrossRef]

5. Pinho, E.; Henriques, M.; Oliveira, R.; Dias, A.; Soares, G. 2010 Development of biofunctional textiles by the application of resveratrol to cotton, bamboo, and silk. Fibers Polym. 2016, 11, 271-276. [CrossRef]

6. Massella, D.; Argenziano, M.; Ferri, A.; Guan, J.; Giraud, S.; Cavalli, R.; Barresi, A.; Salaün, F. Bio-functional textiles: Combining pharmaceutical nanocarriers with fibrous materials for innovative dermatological therapies. Pharmaceutics 2019, 11, 403. [CrossRef]

7. Hipler, U.C.; Elsner, P. Biofunctional Textiles and the Skin. In Current Problems in Dermatology, 1st ed.; Itin, P., Jemec, G.B.E., Eds.; Karger: Basel, Switzerland, 2006; Volume 33.

8. Carosio, F.; Cuttica, D.; di Blasio, A.; Alongi, J.; Malucelli, G. Layer by layer assembly of flame retardant thinfilms on closed cell PET foams: Efficiency of ammonium polyphosphate versus DNA. Polym. Degrad. Stab. 2015, 113, 189-196. [CrossRef]

9. Ferri, A.; Kumari, N.; Peila, R.; Barresi, A.A. Production of menthol-loaded nanoparticles by solvent displacement. Can. J. Chem. Eng. 2017, 95, 1690-1706. [CrossRef]

10. Ghayempour, S.; Montazer, M. Tragacanth Nanocapsules containing chamomile extract prepared through sono-assisted W/O/W microemulsion and UV cured on cotton fabric. Carbohydr. Polym. 2017, 170, 234-240. [CrossRef]

11. Massella, D.; Ancona, A.; Garino, N.; Cauda, V.; Guan, J.; Salaun, F.; Barresi, A.A.; Ferri, A. Preparation of bio-functional textiles by surface functionalisation of cellulose fabrics with caffeine loaded nanoparticles. IOP Conf. Ser. Mater. Sci. Eng. 2018, 460, 012044. [CrossRef]

12. Massella, D.; Celasco, E.; Salaün, F.; Ferri, A.; Barresi, A. Overcoming the limits of flash nanoprecipitation: Effective loading of hydrophilic drug into polymeric nanoparticles with controlled structure. Polymers 2018, 10, 1092. [CrossRef]

13. Rivero, P.; Urrutia, A.; Goicoechea, J.; Arregui, F. Nanomaterials for functional textiles and fibers. Nanoscale Res. Lett. 2015, 10, 501. [CrossRef]

14. Silva, A.; Silvestre, A.; Freire, C.; Vilela, C. Modification of textiles for functional applications. In Fundamentals of Natural Fibres and Textiles; Textile Institute Book series; Elsevier: Amsterdam, The Netherlands, 2021; pp. 303-365.

15. Gao, Y.; Cranston, R. Recent advances in antimicrobial treatments of textiles. Text. Res. J. 2008, 78, 60-72. 
16. Ristić, T.; Zemljič, L.F.; Novak, M.; Kunčič, M.K. Antimicrobial efficiency of functionalised cellulose fibres as potential medical textiles. In Science against Microbial Pathogens: Communicating Current Research and Technological Advances; Méndez-Vilas, A., Ed.; Formatex Research Center: Badajoz, Spain, 2011.

17. Glazer, A.N.; Nikaido, H. Microbial Biotechnology: Fundamentals of Applied Microbiology; Cambridge University Press: Cambridge, UK, 2007.

18. Sun, G. Antibacterial textile materials for medical applications. In Functional Textiles for Improved Performance, Protection and Health; Woodhead Publishing: Sawston, UK, 2011; pp. 360-375.

19. Hegstad, K.; Langsrud, S.; Lunestad, B.; Scheie, A.; Sunde, M.; Yazdankhah, S. Does the wide use of quaternary ammonium compounds enhance the selection and spread of antimicrobial resistance and thus threaten our health? Microb. Drug Resist. 2010, 16, 91-104. [CrossRef]

20. Kramer, A.; Guggenbichler, P.; Heldt, P.; Jünger, M.; Ladwig, A.; Thierbach, H.; Weber, U.; Daeschlein, G. Hygienic relevance and risk assessment of antimicrobial-impregnated textiles. Curr. Probl. Dermatol. 2006, 33, 78-109.

21. Windler, L.; Height, M.; Nowack, B. Comparative evaluation of antimicrobials for textile applications. Environ. Int. 2013, 53, 62-73. [CrossRef]

22. Islam, S.-U.; Shahid, M.; Mohammad, F. Perspectives for natural product-based agents derived from industrial plants in textile applications-A review. J. Clean. Prod. 2013, 57, 2-18. [CrossRef]

23. Upadhyay, A.; Upadhyaya, I.; Kollanoor-Johny, A.; Venkitanarayanan, K. Combating pathogenic microorganisms using plantderived antimicrobials: A minireview of the mechanistic basis. BioMed Res. Int. 2014, 2014, 761741. [CrossRef]

24. Savoia, D. Plant-derived antimicrobial compounds: Alternatives to antibiotics. Future Microbiol. 2012, 7, 979-990. [CrossRef]

25. Sheikh, J.; Bramhecha, I. Enzymes for green chemical processing of cotton. In The Impact and Prospects of Green Chemistry for Textile Technology; ul-Islam, S., Butola, B.S., Eds.; Woodhead Publishing: Sawston, UK, 2019; pp. 135-160.

26. Eid, B.; Ibrahim, N. Recent developments in sustainable finishing of cellulosic textiles employing biotechnology. J. Clean. Prod. 2021, 284, 124701. [CrossRef]

27. Purwar, R.; Joshi, M. Recent developments in antimicrobial finishing of textiles. AATCC Rev. 2004, 4, 22-26.

28. Joshi, M.; Wazed, S.; Purwar, R.; Rajendran, S. Eco-friendly antimicrobial finishing of textiles using bioactive agents on natural products. Indian J. Fibre Text. Res. 2009, 34, 295-304.

29. Singh, R.; Jain, A.; Panwar, S.; Gupta, D.; Kharea, S.K. Antibacterial activity of some natural dyes. Dyes Pigment 2005, 66, 99-102. [CrossRef]

30. Scalbert, A. Antimicrobial properties of tannins. Phytochemistry 1991, 30, 3875-3883. [CrossRef]

31. Vastrad, J.V.; Goudar, G.; Byadgi, S.A. Characterisation of phenolic compounds in eucalyptus globulus and cymbopogan citratus leaf extracts. Bioscan 2016, 11, 2153-2156.

32. Jaswal, P.; Preet, A.; Simran; Goel, G. Antimicrobial activity of herbal treated cotton fabric. Int. Res. J. Eng. Technol. 2017, 4, 39-43.

33. Ijarotimi, O.; Adeoti, O.; Ariyo, O. Comparative study on nutrient composition, phytochemical, and functional characteristics of raw, germinated, and fermented Moringa oleifera seed flour. Food Sci. Nutr. 2013, 1, 452-463. [CrossRef]

34. Gopalakrishnan, L.; Doriya, K.; Kumar, D.S. Moringa oleifera: A review on nutritive importance and its medicinal application. Food Sci. Hum. Wellness 2016, 5, 49-56. [CrossRef]

35. Viera, G.; Mourão, J.; Ângelo, Â.; Costa, R.; Vieira, R. Antibacterial effect (in vitro) of Moringa oleifera and annona muricata against gram positive and gram-negative bacteria. Rev. Inst. Med. Trop. São Paulo 2010, 52, 129-132. [CrossRef]

36. Rockwood, J.L.; Anderson, B.G.; Casamatta, D.A. Potential uses of Moringa oleifera and an examination of antibiotic efficacy conferred by $\mathrm{M}$ oleiefera see and leaf extracts using crude extraction methods available to underserved indigenous population. Int. J. Phototherapy Res. 2013, 3, 61-71.

37. Atef, N.; Shanab, S.; Negm, S.; Abbas, Y. Evaluation of antimicrobial activity of some plant extracts against antibiotic susceptible and resistant bacterial strains causing wound infection. Bull. Natl. Res. Cent. 2019, 43, 144. [CrossRef]

38. Maity, P.; Hansda, D.; Bandyopadhyay, U.; Mishra, D.K. Biological activities of crude extracts and chemical constituents of Bael, Aegle marmelos (L.) Corr. Indian J. Exp. Biol. 2009, 47, 849-861. [PubMed]

39. Katayama, T.; Nagai, I. Chemical significance of the volatile components of spices in the food preservative viewpoint-IV. Nippon Suisan Gakkaishi 1960, 26, 29-32. [CrossRef]

40. Duke, J.A. Handbook of Biologically Active Phytochemicals and Their Activities; CRC Press: Boca Raton, FL, USA, 1992.

41. Pub Chem. National Library of Medicine. 2021. Available online: https:/ / pubchem.ncbi.nlm.nih.gov/ (accessed on 17 May 2021).

42. George, M.; Venkataraman, P.R.; Pandalai, K.M. Investigations on plant antibiotics, part II A search ofr antibiotic substance in some Indian medicinal plants. J. Sci. Ind. Res. 1947, 6B, 42.

43. Joshi, C.G.; Magar, N.G. Antibiotic activity of some Indian medicinal plants. J. Sci. Ind. Res. 1952, $11 B, 261$.

44. Pitre, S.; Srivastava, S.K. Pharmacological, microbiological and phytochemical studies on the root of Aegle marmelos. Fitoterapia 1987, 58, 194. [CrossRef]

45. Pandey, D.K.; Asthana, A.; Tripathi, N.N.; Dixit, S.N. Volatile plant products vis-à-vis potato pathogenic bacteria. Ind. Perf. 1981, $25,10-14$.

46. Lambert, J.; Shurvell, H.; Lightner, D.; Cooks, R. Introduction to Organic Spectroscopy; Macmillan: New York, NY, USA, 1987. 
47. Peter Wuelfing, W.; Kosuda, K.; Templeton, A.; Harman, A.; Mowery, M.; Reed, R. Polysorbate 80 UV/vis spectral and chromatographic characteristics-Defining boundary conditions for use of the surfactant in dissolution analysis. J. Pharm. Biomed. Anal. 2006, 41, 774-782. [CrossRef]

48. Dhongade, H.; Paikra, B.; Gidwani, B. Phytochemistry and pharmacology of Moringa oleifera lam. J. Pharmacopunct. 2017, 20, 194-200. [CrossRef]

49. Murugesan, K.; Ezhilarasu, A.; Gajendiran, K. Phytochemical screening, antioxidant and antimicrobial activity of Aegle marmelos from Kolli Hills. Int. J. Interdiscip. Res. Rev. 2013, 1, 10-15.

50. Yousefi, M.; Nateghi, L.; Rezaee, K. Investigation of physicochemical properties, fatty acids profile and sterol content in malaysian coconut and palm oil. Ann. Biol. Res. 2013, 4, 214-219.

51. AATCC 100. Assessment of Antibacterial Finishes on Textile Materials: Developed by American Association of Textile Chemists and Colorists; American Association of Textile Chemists and Colorists: Research Triangle Park, NC, USA, 2019.

52. AATCC 147. Antibacterial Activity Assessment of Textile Materials: Parallel Streak Method Developed by American Association of Textile Chemists and Colorists; American Association of Textile Chemists and Colorists: Research Triangle, NC, USA, 2016.

53. AATCC 30-III. Assessment of Antifungal Activity on Textile Materials: Agar Plate Developed by American Association of Textile Chemists and Colorists; American Association of Textile Chemists and Colorists: Research Triangle, NC, USA, 2013.

54. ASTM 5035-11. Standard Test Method for Breaking Force and Elongation of Textile Fabrics (Strip Method) ASTM (American Society for Testing and Materials) International; ASTM: West Conshohocken, PA, USA, 2019.

55. IS 15370. Indian Standard for Domestic Washing and Drying Procedure for Textile Testing; Standard identical to ISO 6330: New Delhi, India, 2000/2005.

56. Korgaonkar, S.; Sayed, U. Nano herbal oils application on nonwovens. Int. J. Pharm. Res. 2021, 13, $1965-1970$.

57. Rajendran, R.; Radhai, R.; Kotresh, T.; Csiszar, E. Development of antimicrobial cotton fabrics using herb loaded nanoparticles. Carbohydr. Polym. 2013, 91, 613-617. [CrossRef]

58. Aja, P.; Nwachukwu, N.; Ibiam, U.; Igwenyi, I.; Offor, C.; Orji, U. Chemical constituents of Moringa oleifera leaves and seeds from Abakaliki, Nigeria. Am. J. Phytomed. Clin. Ther. 2014, 2, 310-321.

59. Abidi, N.; Cabrales, L.; Haigler, C. Changes in the cell wall and cellulose content of developing cotton fibers investigated by FTIR spectroscopy. Carbohydr. Polym. 2014, 100, 9-16. [CrossRef]

60. Innovation in Textiles. Antimicrobial Textiles Market to Reach \$12.3 billion. 2019. Available online: https://www. innovationintextiles.com/antimicrobial-textiles-market-to-reach-123-billion/ (accessed on 5 August 2020).

61. Venkatraman, P.D.; Sayed, U.; Parte, S.; Korgaonkar, S. Consumer perception of environmentally friendly antimicrobial textiles: A case study from India. Int. J. Adv. Sci. Eng. 2021, 10, 1782-1793.

62. Muhuha, A.W.; Kang'ethe, S.K.; Kirira, P.G. Antimicrobial activity of Moringa oleifera, aloe vera and warbugia ugandensis on multidrug resistant escherichia coli, pseudomonas aeruginosa and staphylococcus aureus. Int. J. Antimicrob. Agents 2018, 4, 168.

63. Dike-Ndudim, J.N.; Anyanwu, G.O.; Egbuobi, R.C.; Okorie, H.M.; Udujih, H.I.; Nwosu, D.C.; Okolie, N.J.C. Anti-bacterial and phytochemical potential of Moringa oleifera leaf extracts on some wound and enteric pathogenic bacteria. Eur. J. Bot. Plant Sci. Phytol. 2016, 3, 50-60.

64. Dzotam, J.K.; Touani, F.K.; Kuete, V. Antibacterial and antibiotic-modifying activities of three food plants (Xanthosoma mafaffa Lam., Moringa oleifera (L.) schott and passiflora edulis sims) against multidrug-resistant (MDR) gram-negative bacteria. BMC Complement Altern. Med. 2016, 16, 9. [CrossRef]

65. Caceres, A.; Cabrera, O.; Morales, O.; Mollinedo, P.; Mendia, P. Pharmacological properties of Moringa oleifera: Preliminary screening for antimicrobial activity. J. Ethnopharmacol. 1991, 33, 213-216. [CrossRef]

66. Balasubramanian, S.; Dama, G.; Surya Narayana, V.V.S.; Reddy, S. GC-MS analysis of the curry leaves (Murraya Koengii). Glob. J. Biol. Agric. Health Sci. 2014, 3, 3-10.

67. Gopala Krishna, A.G.; Raj, G.; Bhatnagar, A.S.; Prasanth Kumar, P.K.; Chandrashekar, P. Coconut oil: Chemistry, production and its applications-A review. Indian Coconut J. 2010, 73, 15-27.

68. Moigradean, D.; Poiana, M.-A.; Alda, L.-M.; Gogoasa, I. Quantitative identification of fatty acids from walnut and coconut oils using GC-MS method. J. Agroaliment. Process. Technol. 2013, 19, 459-463.

69. Dayrit, F. The properties of lauric acid and their significance in coconut oil. J. Am. Oil Chem. Soc. 2014, 92, 1-15. [CrossRef]

70. Sales-Campos, H.; Reis de Souza, P.; Crema Peghini, B.; Santana da Silva, J.; Ribeiro Cardoso, C. An overview of the modulatory effects of oleic acid in health and disease. Mini Rev. Med. Chem. 2013, 13, 201-210.

71. Monolaurin. What is Monolaurin? 2021. Available online: https://www.healthline.com/health/monolaurin (accessed on 12 July 2021).

72. Nakatsuji, T.; Kao, M.; Fang, J.; Zouboulis, C.; Zhang, L.; Gallo, R.; Huang, C. Antimicrobial property of lauric acid against propionibacterium acnes: Its therapeutic potential for inflammatory acne vulgaris. J. Investig. Dermatol. 2009, 129, $2480-2488$. [CrossRef]

73. Health Line. What is Lauric Acid? 2021. Available online: https://www.healthline.com/health/beauty-skin-care/what-is-lauricacid\#for-psoriasis (accessed on 12 July 2021). 